\title{
IMINE-BASED ARCHITECTURES AT SURFACES AND INTERFACES: FROM SELF-ASSEMBLY TO DYNAMIC COVALENT CHEMISTRY IN 2D
}

Iwona Janica, ${ }^{[a, b]}$ Violetta Patroniak, ${ }^{[a]}$ Paolo Samorì, ${ }^{*}[c]$ Artur Ciesielski* ${ }^{*,[c]}$

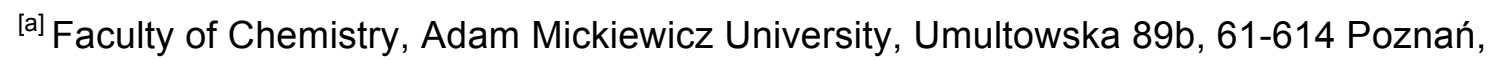
Poland

${ }^{[b]}$ Centre for Advanced Technologies, Adam Mickiewicz University, Umultowska 89c, 61-614 Poznań, Poland

${ }^{[c]}$ Université de Strasbourg, CNRS, ISIS, 8 allée Gaspard Monge, 67000 Strasbourg, France E-mail : samori@unistra.fr, ciesielski@unistra.fr
} 


\section{ABSTRACT}

During the last two decades dynamic covalent chemistry (DCC) has emerged as an efficient and versatile strategy for the design and synthesis of complex molecular systems in solution. While early examples of supramolecularly assisted covalent synthesis at surfaces relied strongly on kinetically controlled reactions for post-assembly covalent modification, the DCC method takes advantage of the reversible nature of bond formation and allows the generation of the new covalently bonded structures under thermodynamic control. These structurally complex architectures obtained via DCC protocols offer a wealth of solutions and opportunities towards the generation of new complex materials holding sophisticated properties.

In this Focus Review we focus on the formation of covalently bonded imine-based discrete nanostructures, as well as one-dimensional (1D) polymers and two-dimensional (2D) covalent organic frameworks (COFs) physisorbed on solid substrates under various experimental conditions, e.g. under ultra-high vacuum (UHV) or at the solid/liquid interface. Scanning tunneling microscopy (STM) is used to gain insight, with a sub-nanometer resolution, into the structure and properties of those complex nanopatterns. 


\section{INTRODUCTION}

Supramolecular chemistry relies on the use of non-covalent forces to assemble molecular building blocks, with a sub-nanometer precision, to form superstructures and ultimately materials that display programmed chemical and physical properties. ${ }^{[1]}$ Yet, the labile nature of non-covalent interactions highly affects the stability of the self-assembled structures both in liquid media and in the solid-state, thereby jeopardizing their use in technologically relevant applications. In this regard, the necessity of creating molecular architectures based on chemical components that interact through more robust, yet reversible bonds, gave rise to the field of dynamic covalent chemistry (DCC). ${ }^{[1-2]}$ Noteworthy, DCC shares various features with supramolecular chemistry; in particular, they both rely on reversible bonds that enable the formation of complex structures and materials under thermodynamic control. ${ }^{[2-6]}$ Both DCC and supramolecular chemistry are adaptable and modular because they allow for the selection and exchange of molecular components. On the other hand, there are some major differences between these two types of reversible chemical approaches. The equilibration processes are much faster in supramolecular systems when compared to DCC ones, because in the latter the covalent bonds need to be broken and reformed. Furthermore, DCC allows generation of structures, which are by nature more durable than the structures produced by supramolecular chemistry. For these reasons DCC is emerging as a versatile and efficient approach for the design and synthesis of complex molecular structures, which are chemically and mechanically stable. ${ }^{[1,7-9]}$

In DCC both internal and external factors such as concentration, temperature, pressure or presence of impurities, can have a significant effect on the equilibrium and distribution of products, even after the formation of the targeted product. This variable range of parameters allows designing and creating compounds, which can adjust to the environment. $^{[10]}$

While classical covalent chemistry operates under kinetic control, the DCC approach takes advantage of the reversible nature of bond formation to generate new covalent structures under thermodynamic control. ${ }^{[11]}$ In particular, DCC includes the chemistry of disulfide, ${ }^{[12-13]}$ acetal $^{[14-15]}$ and ester, ${ }^{[16-17]}$ oxime, ${ }^{[18]}$ boroxine,${ }^{[19-20]}$ alkynes ${ }^{[21]}$ and imines ${ }^{[22-29]}$ to allow the generation of new covalent structures. Chemical groups that include a $\mathrm{C}=\mathrm{N}$ or carbonyl units, such as imines, esters or amides, are of particular interest since they can undergo disconnection/reconnection cycles (e.g. trans reactions like esterification, imination and amidation). Especially, the reversible nature of imine bonds makes them attractive for being used in DCC, because the (carbonyl + amine) condensation into imine-type compounds usually takes place under mild conditions. ${ }^{[2-5,30-32]}$ It is now well established that imines can participate to three types of equilibrium-controlled reactions: $i$ ) hydrolysis - the 
imine reverts back to the precursors, i.e. amine- and carbonyl- containing compounds; ii) transamination - upon introduction of a second amine (or carbonyl), the original imine undergoes an exchange of the amine residue to give a new imine; iii) imine-imine exchange - upon introduction of a second imine, the two imines can undergo a reaction whereby the amine components are exchanged. ${ }^{[33]}$ Noteworthy, dynamic exchanges that involve the $\mathrm{C}=\mathrm{N}$ bonds in imines, hydrazones and oximes are the most widely used DCC reactions. They have been applied to the syntheses of complex two-dimensional (2D) and three-dimensional (3D) systems such as covalent organic frameworks (COFs). ${ }^{[34]}$

The need to explore matter at the sub-molecular scale in the direct space has made scanning tunneling microscopy (STM) a widely employed and extremely powerful tool to study surfaces and interfaces. ${ }^{[35-45]}$ Since its invention in 1982, ${ }^{[46]}$ STM is commonly exploited to bestow electronic and chemical information onto supramolecular assemblies. ${ }^{[35-36,47-50]}$ The sub-nanometer resolution that can be achieved with STM makes it possible to acquire thorough insight into intra- and intermolecular molecular interactions; thus, it is an essential tool to assist in the design of (supra)molecular modules that undergo controlled assembly at solid substrates under various experimental conditions (concentration, ${ }^{[51]}$ temperature ${ }^{[52]}$ and pressure ${ }^{[53]}$ ) to generate the superstructures. Beyond the mere imagining of the physisorbed monolayers, ${ }^{[54-55]}$ recent studies have demonstrated that STM is the most powerful tool to study physical and chemical properties of nanostructures via, e.g. molecule manipulation, ${ }^{56-}$ ${ }^{60]}$ monitoring of molecular dynamics ${ }^{[43,61]}$ and surface chirality, ${ }^{[62]}$ etc.

Currently, STM investigations of molecular adsorption can be achieved under various environmental conditions, e.g., under ultra-high vacuum (UHV), at the solid/liquid and at the solid/air interfaces. The latter represents a remarkably versatile environment for the selfassembly of molecular building blocks, and offers numerous advantages, if compared to STM operating under UHV. In particular, the molecules physisorbed at the solid-liquid interface are at the thermodynamic equilibrium with those solvated in the $3 \mathrm{D}$ supernatant solution. As a result, dynamic adsorption/desorption processes take place, thereby fostering self-healing of defects in self-assembled monolayers. ${ }^{[63]}$ Moreover, STM operating at the solid/liquid interface offers the possibility of screening the changes in the structural motifs of molecular monolayers upon exposure to external physical or chemical stimuli, e.g., by varying the temperature, ${ }^{[64]}$ irradiation with UV light, ${ }^{[65]}$ coordination of metallic centers to organic ligands, ${ }^{[66-68]}$ or by changing the $\mathrm{pH} .{ }^{[69]}$ Noteworthy, such modifications can occur in a reversible manner, while under UHV molecular re-organizations are mostly irreversible.

Herein, we will discuss the engineering of one-dimensional (1D) and two-dimensional (2D) imine-based supramolecular structures through the self-association of aldehydes and amines on atomically flat, solid substrates, as explored by STM operating at the solid/liquid interface and under UHV. In the first section (2.1), we focus on the recent examples of 
discrete imine-based assemblies. Further on, in (2.2) we give a perspective into the strategies employed for bottom-up fabrication of 1D polymers. In the final section (2.3) we address the on-surface in situ Schiff-base condensation between aldehydes and amines as a path towards extended 2D imine-based COFs.

\section{DISCUSION}

Recently, on-surfaces covalent chemistry has attracted a great attention and it is now being exploited to direct the topology of the resulted nanostructures. On the one hand, the on-surface covalent chemistry has unique features from the viewpoint of fundamental surface science. At a first glance, the chemical reactions taking place on the surface appear quite similar to the corresponding bulk reaction, since they are based on the same reaction precursors and reaction process. Yet, during the reaction the substrate surface is not only a passive element, i.e. a solid support, but it can play an active role. For example, if one compares the same condensation reaction taking place at the solid/liquid interface or in solution, the former is usually faster, due to higher local concentration at the solid/liquid interface compared to the one existing in the $3 \mathrm{D}$ solution. In other words, confinement in quasi-2D eases the reaction by decreasing activation barrier. ${ }^{[70]}$ For example, the formation of the same quantity of the condensation product at the solid/liquid interface can be as $10^{4}$ times faster than in solution. ${ }^{[1]}$ Furthermore, the on-surface synthesis represents a facile route towards novel nanostructures that cannot be generated by other methods. For example, surface can be used as template to support the synthesis of 2D polymers, which cannot be obtained from classical solution-phase route. ${ }^{[72]}$

General method towards synthesis of imines at the solid/liquid and solid/gas interface relies either on co-deposition of a mixture of the monomers or on the formation of monolayer of aldehyde and subsequent addition of amine on the top of pre-existing aldehyde assembly. The organic solvents employed for STM measurements need to combine certain characteristics: $i$ ) be a good solvent for the compound under study, ii) have a low affinity for the substrate, i.e., have a low tendency to physisorb onto its surface, iii) possess a low vapour pressure, enabling measurements to be carried out with the tip immersed inside one drop of solution (ca. 5-20 $\mu \mathrm{L}$ ) without the necessity of employing a sealed fluid cell, and $i v$ ) be electrochemically inert under experimental conditions. In most cases, aldehydes and amines are dissolved in 1-phenyloctane or in octanoic acid. Rarely, small amount of pyridine is employed in order to increase the solubility of amines. ${ }^{[71]}$ Noteworthy, the surface mobility and intermolecular interactions between monomers have similar impact on the on-surface polymerization carried out in ultra-high vacuum (UHV) and at the solid/liquid interface. An interplay of the adsorption processes and DCC leads to a shift in the equilibrium thus favoring the formation of the imines with higher affinity towards HOPG, which indicates a 
surface-induced selection of the imines that presents the thermodynamically most-stable physisorption.

\subsection{DISCRETE ASSEMBLIES - IMINES}

Initially, surface-supported syntheses of imines have been carried out on singlecrystal metallic substrates. For example, the on-surface condensation between dialdehyde 11 (Figure 1) and amine 18 (Figure 2) could be accomplished under UHV. Weigelt and coworkers firstly deposited $\mathbf{1 1}$ on the $\mathrm{Au}(111)$ and then exposed the self-assembled monolayer to the vapors of octylamine (18) $\left(1-5 \times 10^{-8} \mathrm{mbar}\right) \cdot{ }^{[73]}$ The dialdehyde 11 physisorbs with its backbone oriented parallel to the basal plane of the substrate and forms well-ordered structures (Figure $3 b$ ); with the bright protrusions at the extremities of the molecules can be ascribed to the tert-butyl groups of 11 . On the other hand, the amine 18 forms a densely packed lamellar structure as displayed in Figure 3c.
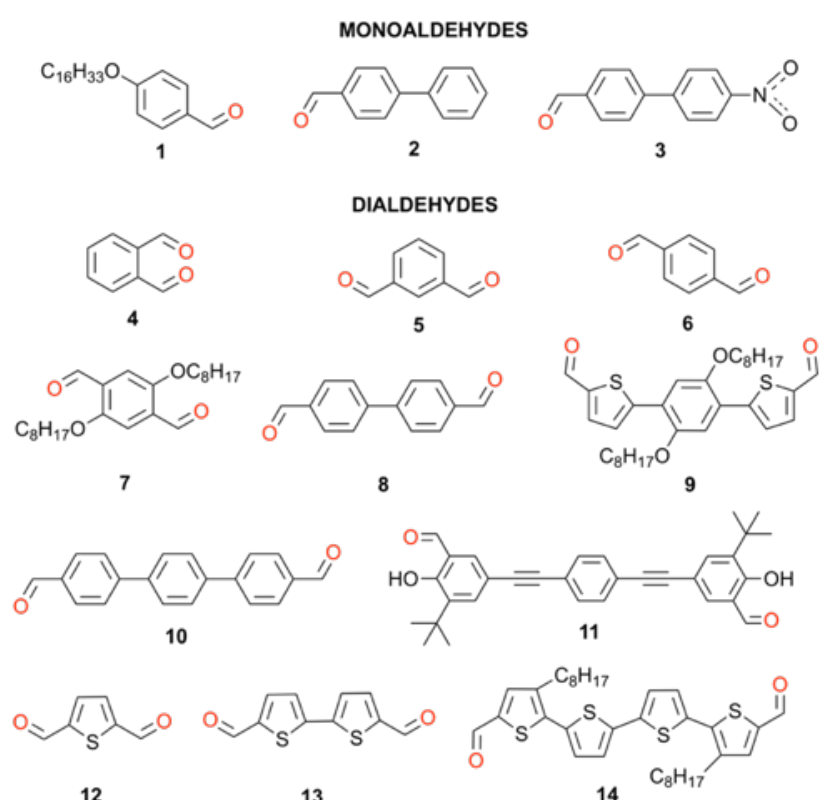

14

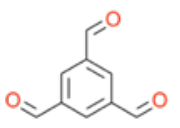

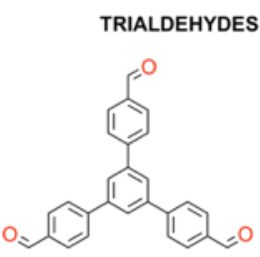

16

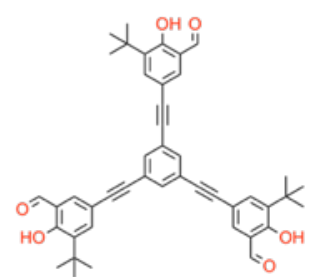

17

Figure 1. Chemical structure of investigated aldehydes: Monoaldehydes: (1) 4-(hexadecyloxy)benzaldehyde; (2) 4-biphenylcarboxaldehyde; (3) 4'-nitro[1,1'-biphenyl]-4-carbaldehyde; Dialdehydydes: (4) phthalaldehyde; (5) isophthalaldehyde; (6) terephthalaldehyde; (7) 2,5-bis(octyloxy)terephthalaldehyde; (8) [1,1'-biphenyl]-4,4'dicarbaldehyde; (9) 5,5'-(2,5-bis(octyloxy)-1,4-phenylene)bis(thiophene-2-carbaldehyde); (10) [1,1'4'-terphenyl]4,4"-dicarbaldehyde; (11) 5,5'-(1,4-phenylenebis(ethyne-2,1-diyl))bis(3-(tert-butyl)-2-hydroxybenzaldehyde); (12) 2,5-thiophenedicarboxaldehyde; (13) [2,2'-bithiophene]-5,5'-dicarbaldehyde; (14) 3,3"'-dioctyl-[2,2':5',2":5",2"'quaterthiophene]-5,5"'-dicarbaldehyde; Trialdehydes: (15) 1,3,5-triformylbenzene; formylphenyl)benzene; (17) 1,3,5-tris[(5-tert-butyl-3-formyl-4-hydroxyphenyl)ethynyl]benzene.

(16) 1,3,5-tris $(4-$ 

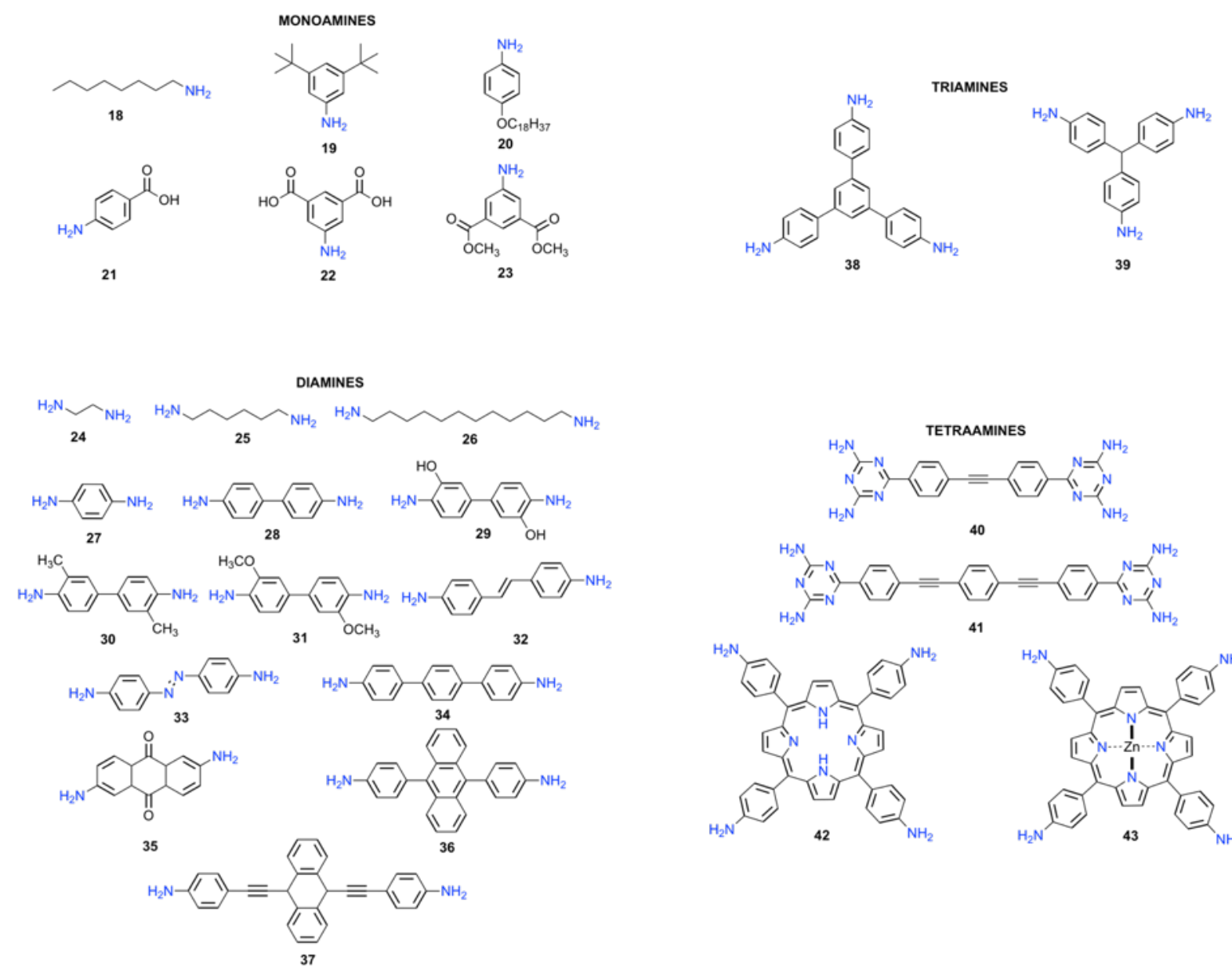

Figure 2. Chemical structure of investigated amines: Monoamines: (18) octylamine; (19) 3,5-di-tert-butylaniline; (20) 4-(octadecyloxy)anilinę; (21) 4-aminobenzoic acid; (22) 5-aminoisophthalic acid; (23) dimethyl 5aminoisophthalate; Diamines: (24) 1,2-diaminoethane; (25) 1,6-diaminohexane; (26) 1,12-diaminododecane; (27) p-phenylenediamine; (28) benzidine; (29) 3,3'-dihydroxybenzidine; (30) o-tolidine; (31) 3,3'-dimethoxybiphenyl4,4'-diamine; (32) 4,4'-diaminostilbene; (33) 4,4'-azodianiline; (34) 4,4"-diamino-p-terphenyl; (35) 2,6diaminoanthraquinone; (36) 9,10-bis(p-aminophenylethynyl)anthracene; (37) 4,4'-((9,10-dihydroanthracene-9,10diyl)bis(ethyne-2,1-diyl))dianiline. Triamines: (38) tris(4-aminophenyl)benzene; (39) 4,4',4"-methylidyne(trianiline). Tetraamines: (40) 6,6'-(ethyne-1,2-diylbis(4,1-phenylene))bis(1,3,5-triazine-2,4-diamine); (41) 6,6'-((1,4phenylenebis(ethyne-2,1-diyl))bis(4,1-phenylene))bis(1,3,5-triazine-2,4-diamine); (43) 5,10,15,20-meso-tetra(4aminophenyl)porphyrin; (43) 5,10,15,20-meso-tetra(4-aminophenyl)porphyrin Zn(II).

Upon condensation of the two components, highly ordered $\mathbf{1 8}_{\mathbf{2}} \mathbf{1 1}$ structures appear on $\mathrm{Au}(111)$ surface (Figure $3 \mathrm{~d}$ and $3 e$ ). The protrusions in the STM images associated with the tert-butyl groups form parallel rows with the aromatic backbone visible between two bright protrusions belonging to neighboring rows. Alkyl chains from adjacent molecules align pair wise, similarly to the lamellar motif observed for the structure of $\mathbf{1 8}$. In order to confirm these results, the bis-imine was synthesized ex situ in solution and subsequently evaporated onto an $\mathrm{Au}(111)$ surface and kept at the temperature of ca. $120 \mathrm{~K}$ (to avoid thermally activated surface reaction): the obtained structures were identical as those resulting from the in situ reactions. 


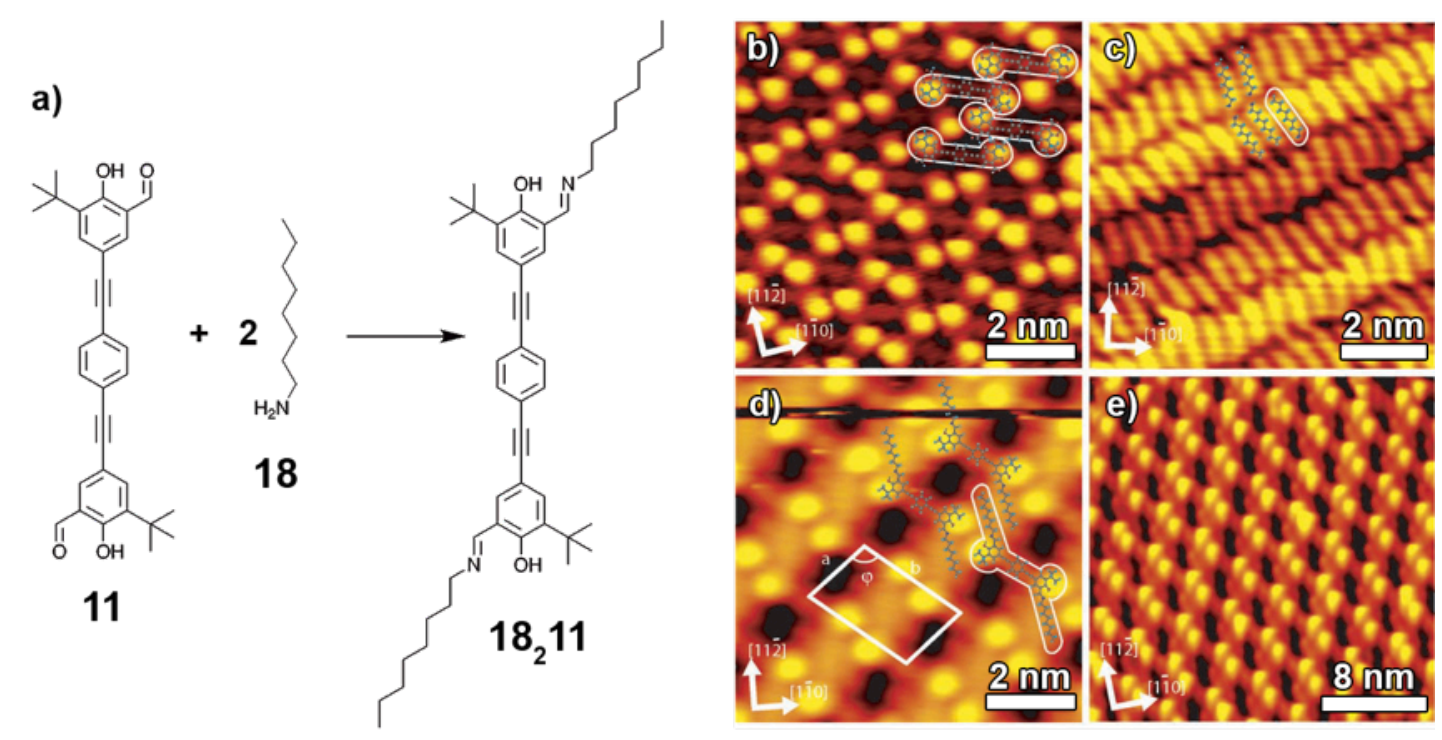

Figure 3. (a) Schematic representation of condensation reaction of aldehyde 11 with amine 18 on a $\mathrm{Au}(111)$ surface. STM images of (b) self-assembled island formed by the dialdehyde 11; (c) lamellar structure formed by 18; (d) self-assembled structure formed by the bis-imine $1 \mathbf{1 8}_{2} 11$ prepared in situ at room temperature. The unit cell of the structure is indicated; (e) large ordered domain formed by the bis-imine prepared in situ. Imaging conditions: (b) $I_{t}=-0.77 n A, V_{t}=-1.0 \mathrm{~V} ;$ (c) $I_{t}=0.41 n A, V_{t}=+2.0 \mathrm{~V} ;(d) I_{t}=0.27 n A, V_{t}=+1.9 V ;(e) I_{t}=-0.42 n A$, $\mathrm{V}_{\mathrm{t}}=-2.2 \mathrm{~V}$, bar size $4 \mathrm{~nm}$. Reproduced from Ref., ${ }^{[73]}$ with permissions of Wiley.

Nevertheless, due to high reversibility, mild reaction conditions and possibility to control Schiff-base reaction by various external stimuli, e.g. concentration or temperature, the solid/liquid interface has appeared superior over UHV in the last decade, as it offers a particularly interesting environment to perform condensation reactions and their in situ investigation by STM.

In 2014, some of us have performed a sub-molecularly resolved STM mapping of the surface-mediated reversible exchange processes of aliphatic bis-imines occurring at the solid/liquid interface on HOPG surface. ${ }^{[71]}$ We have focused our attention on the condensation of 4-(hexadecyloxy)benzaldehyde (1) with three $\alpha, \omega$-diamines of different length, i.e. 1,2-diaminoethene (24), 1,6-diaminohexane (25) and 1,12-diaminododecane (26). Within such a work, we have reported for the first time on the STM studies on the constitutional covalent (reversible) dynamic processes of bis-transimination, i.e. diamine exchange on the bis-imines, as illustrated on Figure 4. In order to fully explore the reversible nature of imine bonds, and to gain insight into the bis-transimination processes of bis-imine molecules, successive in situ imination/bis-transimination cycles were performed. Upon addition of $\mathbf{2 4}$ on top of a pre-existing monolayer of $\mathbf{1}$ (Fig. 4a), the $\mathbf{1} \mathbf{2} \mathbf{2 4}$ motif was obtained (Fig. 4b). Upon subsequent addition of 25 solution, the $\mathbf{1 2} 24$ monolayer was transformed into an $\mathbf{1}_{2} 25$ structure (Fig. 4c). Finally, the addition of a drop of 26 resulted in the formation of $\mathbf{1}_{2} \mathbf{2 6} 2 \mathrm{D}$ pattern (Fig. $4 \mathrm{~d}$ ). Interestingly, the rate of the bis-transimination processes and the formation of the new monolayer structures depends on the length of diamine molecule, e.g. $\mathbf{1} 2 \mathbf{2 4}$ monolayers transform into $\mathbf{1 2}_{2} \mathbf{2 5}$ after ca. $3 \mathrm{~min}$, whereas $\mathbf{1}_{2} \mathbf{2 6}$ monolayers are formed 
after ca. 1 min after addition of 26 solution on top of $\mathbf{1}_{2} \mathbf{2 5}$ structure. This observation was associated to different adsorption energies of bis-imines on HOPG surface, which increase significantly with the length of diamine linker: $33.6 \mathrm{kcal} \mathrm{mol}^{-1}, 59.3 \mathrm{kcal} \mathrm{mol}^{-1}, 71.8 \mathrm{kcal} \mathrm{mol}^{-1}$ and $81.3 \mathrm{kcal} \mathrm{mol}^{-1}$ for $\mathbf{1}, \mathbf{1}_{\mathbf{2}} \mathbf{2 4}, \mathbf{1}_{\mathbf{2}} \mathbf{2 5}$ and $\mathbf{1} \mathbf{2} \mathbf{2 6}$, respectively.
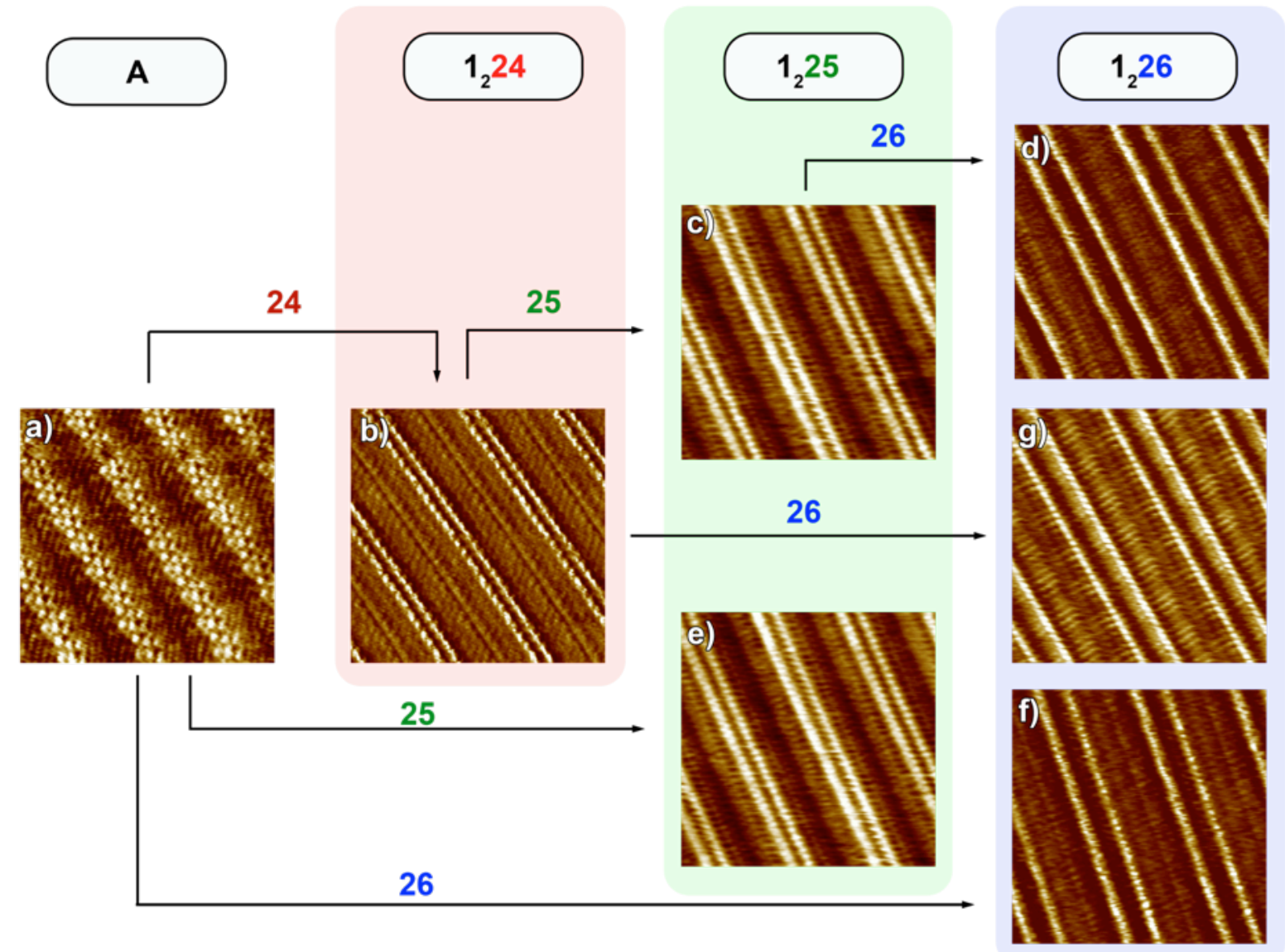

Figure 4. STM representative images of in situ condensation/bis-transimination processes. (a) the monolayer of 1; (b) 1224 motif obtained upon in situ addition of $\mathbf{2 4}$ on top of a pre-existing monolayer of 1; (c) On the subsequent addition of $\mathbf{2 5}$ solution, the $\mathbf{1} 2 \mathbf{2 4}$ monolayer was transformed into an $\mathbf{1}_{\mathbf{2}} \mathbf{2 5}$ structure; (d) the addition of a drop of 26 solution resulted in the formation of an 1226 pattern. (e) Monolayers of 1225 and (f) 1226 can be obtained by depositing a drop of $\mathbf{2 5}$ and $\mathbf{2 6}$ on top of pre-existing monolayers of $\mathbf{1}$. (g) Bis-transimination of $\mathbf{1}_{2} \mathbf{2 4}$ with 26 resulted in the formation of $\mathbf{1 2 2 6}$ monolayers. Tunnelling parameters: $I_{t}=10-15 p A, V_{t}=400-600 \mathrm{mV}$. The size of the STM images $(\mathrm{a}-\mathrm{g})$ is $18 \mathrm{~nm} \times 18 \mathrm{~nm}$. Reproduced from Ref., ${ }^{[71]}$ with permissions of Springer Nature.

The on-surface condensation of trialdehyde 16 with 5-aminoisophthalic acid (22) at the solid/liquid interface was investigated by $\mathrm{Li}$ and co-workers ${ }^{[74]}$ and is shown in Figure 5 . The addition of $\mathbf{2 2}$ on top of existing layer of $\mathbf{1 6}$ at room temperature resulted in formation of open-network connected by hydrogen bonds between carboxylic groups of 22 . Two different cavities appear in the network. One of them is composed of six benzene rings from six triimines, which are connected by hydrogen bonds between the carboxylic groups, while the second type of cavity consists of two tri-imine molecules. The structural transformation of trialdehyde 16 lamellar structures to open network after addition of amine 22 was monitored 
in situ by STM. Upon addition of amine 22 on top of trialdehyde 16, the lamellar structures evolve towards irregular assemblies. After $12 \mathrm{~h}$, defective open-network structures appear, which still exist after $24 \mathrm{~h}$. To confirm the on-surface reaction, ex situ synthesis of tri-imine was conducted; the subsequent deposition on HOPG surface revealed the formation of the open network identical to the one obtained via in situ experiments.

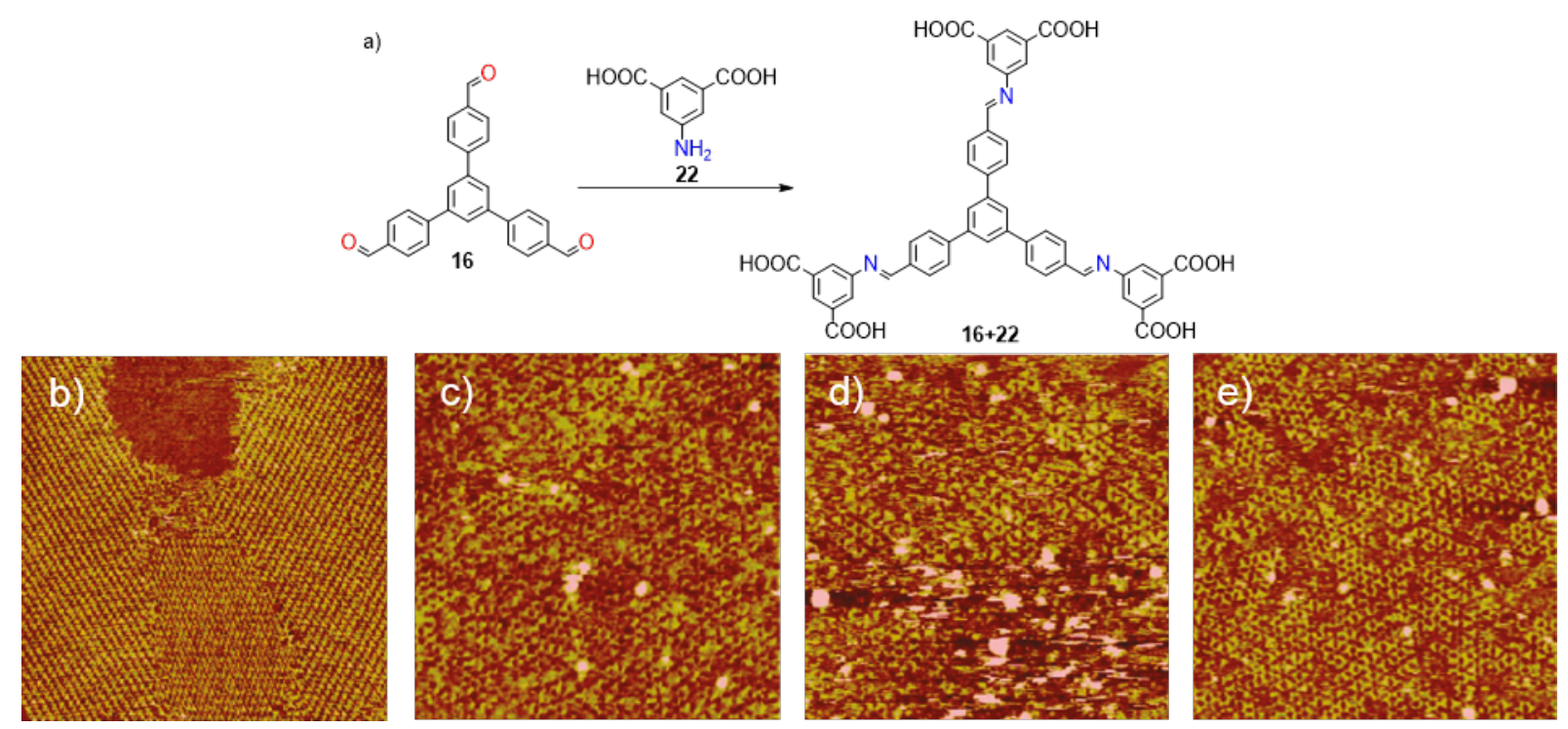

Figure 5. Schematic representation of condensation reaction of aldehyde 16 with amine 22 (a) and series of STM sequence images of a $70.0 \mathrm{~nm} \times 70.0 \mathrm{~nm}$ region illustrating the structural transformation: (b) lamellar structure of aldehyde 16; (c) irregular structure formed upon addition of amine 22 on pre-existing aldehyde 16 layer; (d) the open network after $12 \mathrm{~h}$ and (e) $24 \mathrm{~h}$. Imaging conditions: $V_{\text {bias }}=935.3 \mathrm{mV}$ and $\mathrm{I}_{\mathrm{t}}=223.3 \mathrm{pA}$ ). Reproduced from Ref., ${ }^{[74]}$ with permission of American Chemical Society.

Recently, Plas and co-workers have studied the condensation reactions between aldehyde 6 with amine derivatives 19 and 20. ${ }^{[75]}$ These amino compounds were chosen due to the differences in affinity, i.e. adsorption energy, of reagents and products to HOPG, amorphous carbon and silica. A mixture of reagents $\mathbf{6 , 1 9}$ and 20 in the ratio 1:2:2 in 1phenyloctane was drop-cast on to solid substrates. In the case of HOPG, it was shown that molecular self-assembly at surface is ruled by competitive adsorption. An interplay of the adsorption processes and DCC leads to a shift in the equilibrium thus favoring the formation of the imines with higher affinity towards HOPG, which indicates a surface-induced selection of the imines that presents the thermodynamically most-stable physisorption. According to STM images, as a result of the self-assembly at the solid/liquid interface, two different networks are formed. The former consists of mono-imine $6+20$ with co-adsorbed small amounts of bis-imine $\mathbf{2 0}_{2} \mathbf{6}$ and mixed-imine $6+19+20$, whereas the latter matches with the monolayer formed by $\mathbf{2 0}$, which slowly disappears with time and is being replaced by monoimine $\mathbf{6 + 2 0}$ network (Figure 6). 


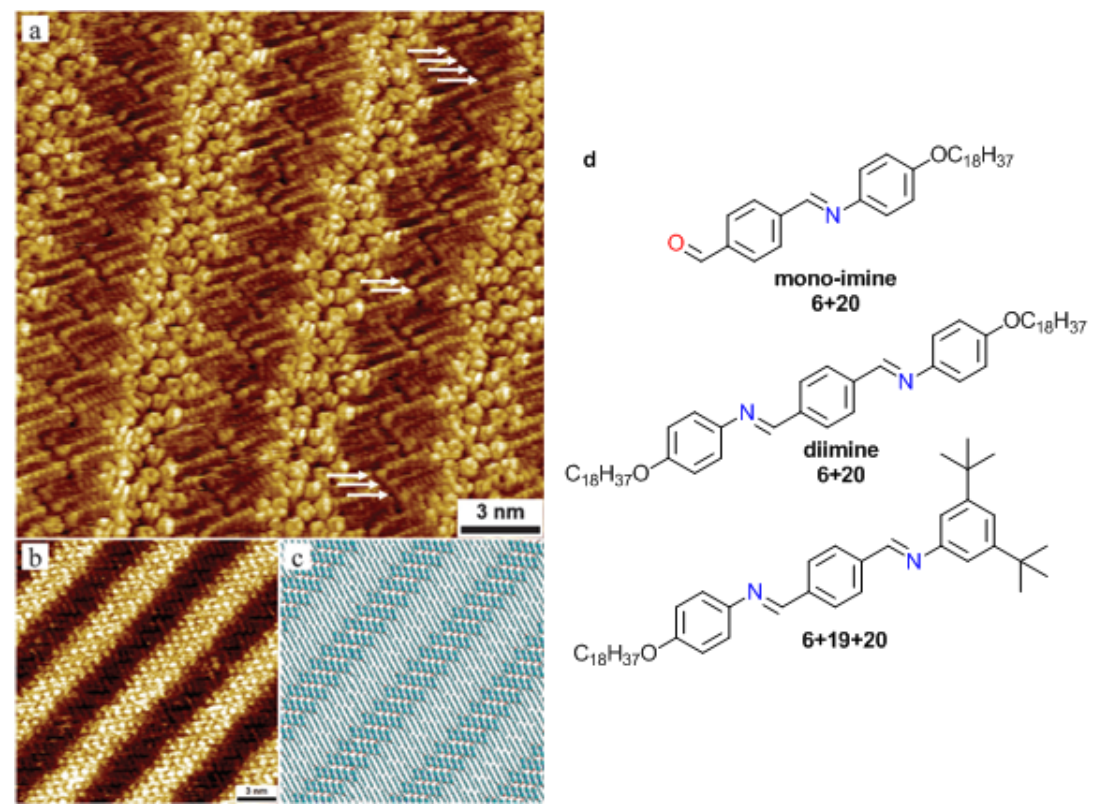

Figure 6. (a) STM-image of products in a monolayer formed after a mixture of 6, 19 and 20 in 1-phenyloctane is drop-casted onto HOPG. (b) STM image of a monolayer of mono-imine $\mathbf{2 0}_{2} \mathbf{6}$ at the 1-phenyloctane/HOPG interface and (c) the corresponding tentative molecular model; (d) chemical structures of formed products during condensation reaction of 6, 19 and 20 at liquid/solid interface on HOPG surface. Reproduced from Ref., ${ }^{[75]}$ with permissions of Royal Society of Chemistry.

The chemical structure of the starting monomers has a great influence on the formation of imine-based nanostructures on surfaces and interfaces. For example, the achiral dialdehyde 14 and two achiral amines (22 and 23) could be combined to form chiral nanostructures as a result of Schiff-base condensation reactions. ${ }^{[76]}$ The amines 22 and 23 were deposited on the top of an existing self-assembled monolayer of dialdehyde 14 supported on HOPG. STM investigations revealed that the adsorption of amine 22 on lamellar monolayer of dialdehyde 14 results in the formation of both clockwise and counterclockwise flower-like structures.

Generally, the monomers used for molecular physisorption at surfaces and interfaces possess a planar conformation, which enable to maximize substrate-molecule interactions thereby stabilizing the formation of self-assembled monolayer. Interestingly, Yue and coworkers showed that non-planar $C_{3}$-symmetrical aromatic amine molecules 39 , when combined with different aromatic aldehydes (2, 3, 8 and 10) can form porous networks on HOPG. ${ }^{[77]}$ Remarkably, while the condensation between tri-amine 39 and dialdehydes should result in the generation of 2D COF, unexpected porous networks of oligomers are obtained. The Schiff-base reaction scheme between 8 and 39 , as well as the STM images of $\left[8_{3} 39\right]_{n}$ network are displayed in Figure 7. It was concluded, that the non-covalent interactions between the oligomers that stabilize the self-assembled networks disfavor the formation of 2D COFs. Within the self-assembled networks, the oligomers self-assemble in antiparallel fashion, and are stabilized via dipole-dipole interactions between the imine bonds and the aldehyde groups $(-\mathrm{N}=\mathrm{C} \cdots \mathrm{O}=\mathrm{C}-)$. Such self-assembly motif precludes the next reaction step, 
i.e. the formation of $2 \mathrm{D}$ COF. Even at higher temperatures (up to $200^{\circ} \mathrm{C}$ ), similar selfassembled structures are observed, suggesting that the self-assembly of the imine oligomer is thermodynamically favored.

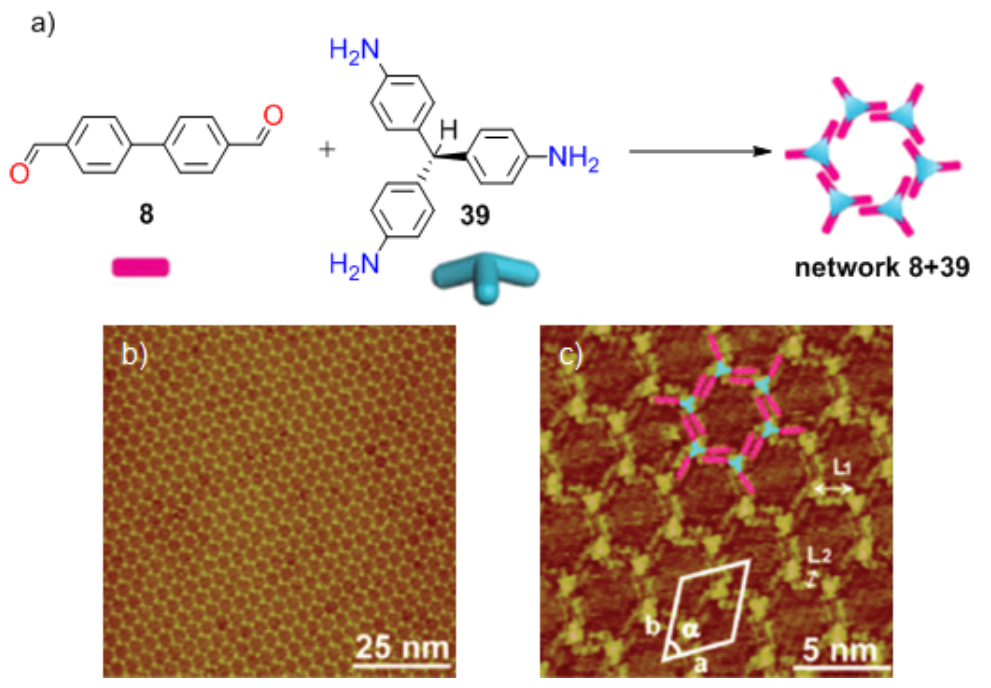

Figure 7. (a) The reaction between 8 and 39 results in the porous network $\left[8_{3} 39\right]_{\mathrm{n}}$. (b) Large-scale and (c) highresolution STM image of network $\left[8_{3} 39\right]_{n}$. Imaging conditions: (b) $l_{t}=500 p A, V_{t}=700 \mathrm{mV}$; (c) $l_{t}=650 p A, V_{t}=$

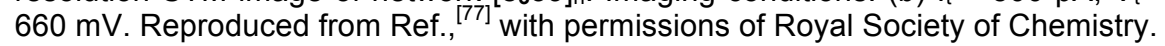

Sun and co-workers exploited 2,5-bis(octyloxy)-terephthalaldehyde (7), 4aminobenzoic acid (21) and 5-aminoisophthalic acid (22) as monomers for the surfaceconfined bis-imine formation. ${ }^{[78]} \mathrm{A}$ drop of a mixture solution of 7, 21 and 22 was applied onto HOPG surface. When the molar ratio of monomer 7, 21 and 22 amounted to 1:2:2, the assembly of bis-imine product $\mathbf{2 2} \mathbf{2}_{\mathbf{2}} \mathbf{7}$ was detected exclusively (Figure $8 \mathrm{a}$ ), indicating that bisimine $22_{2} 7$ is the most favorable species among all the possible products. Even when the molar ratio of monomer $\mathbf{2 1}$ was gradually decreased to 1:0.37:2, the bis-imine $\mathbf{2 2} \mathbf{2}$ was still the predominant specie on HOPG. Noteworthy, at this molar ratio a second type of assembly was monitored at the domains boundaries of bis-imine $\mathbf{2 2} \mathbf{2 7}$. According to the packing mode and orientation, these shorter rods were attributed to mono-imine $22_{1} \mathbf{7}$. As the molar ratio of 21 was further decreased, domains of imine $\mathbf{7 + 2 1}$ were finally visualized with the ratio of 1:0.18:2. At this molar ratio, products $\mathbf{7 + 2 1}$ and $\mathbf{2 2} \mathbf{2} \mathbf{7}$ were found to be the dominant species, with imine $\mathbf{7 + 2 1}$ embedded as defects in domains of $\mathbf{2 2} \mathbf{2} \mathbf{7}$ (Figure $8 \mathrm{~b}$ ). As the monomer molar ratio of 21 further decreased to 1:0.09:2, mono-imine product $\mathbf{7 + 2 1}$ finally became the exclusive specie physisorbed on HOPG (Figure 8c). Moreover, in situ transamination reaction was performed at the octanoic acid/HOPG interface. A deposition of an excessive amount of monomer 22 on an existing monolayer of $\mathbf{7 + 2 1}$, resulted in the formation of the bis-imine $\mathbf{7 + 2 2}$ monolayer. ${ }^{[78]}$ 

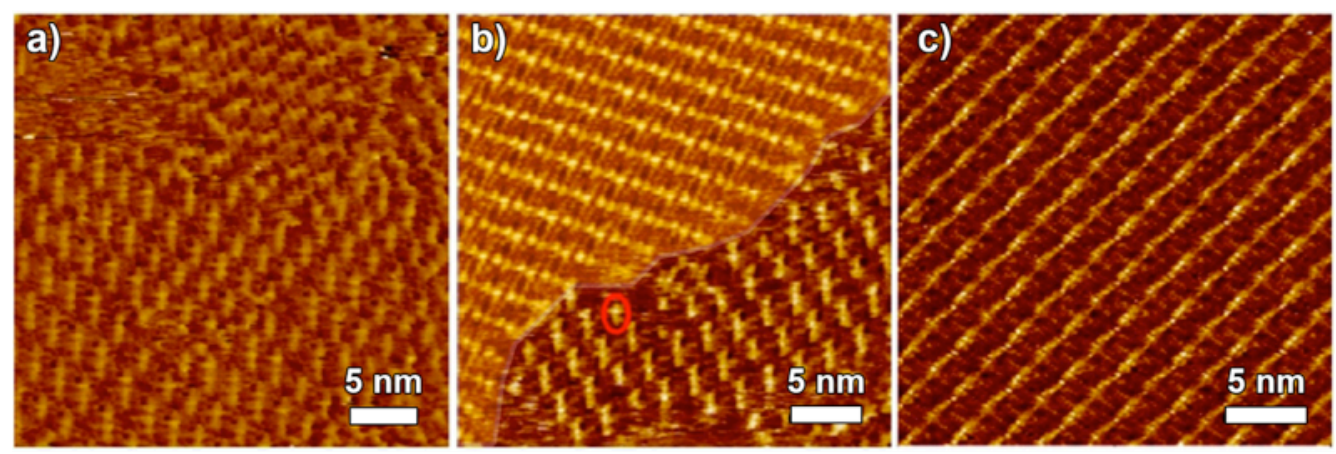

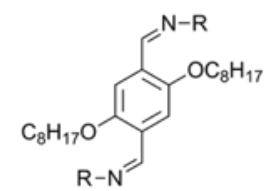

$222_{2} 7$

$\mathrm{R}=$ Ar-3,5-dicarboxyl

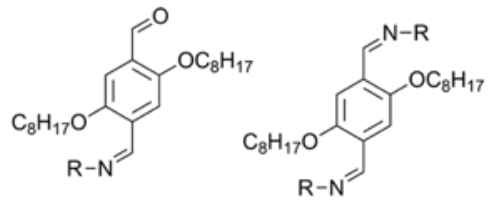

$7+21$

$\mathrm{R}=$ Ar-4-carboxyl $7+22$

$\mathrm{R}=$ Ar-3,5-dicarboxy

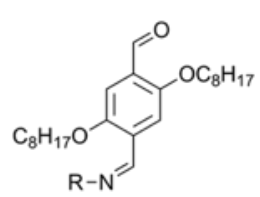

$7+21$

$\mathrm{R}=$ Ar-4-carboxyl

Figure 8. Typical STM images showing the evolution of the monolayer from a tri-component dynamic library of 7 , 21, and 22, and chemical structures of formed (bis-)imines. (a) Bis-imine $\mathbf{2 2} \mathbf{2}$ at molar ratio of monomers 1:2:2 (b) coexistence of imine $\mathbf{7 + 2 1}$ and bis-imine $\mathbf{2 2} \mathbf{2}$ at molar ratio 1:0.18:2 and (c) imine $\mathbf{7 + 2 1}$ at molar ratio 1:0.9:2. A molecule of imine $\mathbf{7 + 2 2}$ is highlighted by a red oval in (b). Tunneling conditions: (a) $I_{t}=40 p A, V_{t}=750 \mathrm{mV}$; (b) $\mathrm{I}_{\mathrm{t}}=40 \mathrm{pA}, \mathrm{V}_{\mathrm{t}}=650 \mathrm{mV}$; (c) $\mathrm{I}_{\mathrm{t}}=35 \mathrm{pA}, \mathrm{V}_{\mathrm{t}}=700 \mathrm{mV}$. Reproduced from Ref. ${ }^{[78]}$ with permissions of American Chemical Society.

In addition, coronene was employed as a template for the introduction of surface structural transformation and promotion of product selection from a tri-component mixture. Upon addition of coronene molecules onto the pre-existing monolayer of diamine $\mathbf{7 + 2 2}$, the lamellar structure transforms intro three guest-induced architectures, featuring Kagome patterns. Yet, some of bis-imines $\mathbf{7 + 2 2}$ were also monitored on the surface. ${ }^{[78]}$

\subsection{ONE-DIMENSIONAL (1D) POLYMERS}

As a result of surface-supported condensation between dialdehydes and diamines, arrays of one-dimensional (1D) imine-based polymers have been generated. Although imines are easily formed at room temperature, ${ }^{[79-80]}$ higher temperatures are sometimes required in order to obtain well-ordered and defect-free imine-based nanostructures. ${ }^{[81]}$ The $1 \mathrm{D}$ polymers produced through surface-supported polymerization, and in particular those which contain extended $\pi$-conjugation, are appealing from a technological viewpoint as they can find use in various applications, e.g. sensors, electronic devices or heterogeneous catalysis. ${ }^{[2]}$

The nature of chemical building blocks and their concentration have significant impact on the self-assembly of 1D polymers at the solid/liquid interface. In 2015, Yu and co-workers performed the on-surface synthesis of ordered linear and zig-zag 1D polymers at HOPG/octanoic acid interfaces. ${ }^{[82]}$ Dialdehydes 5-7 and diamines 27, 28 and 34 were employed to form 1D polymers. In order to gain insights into different parameters of surfacemediated Schiff base coupling, three approaches were investigated: i) monomers were 
dissolved separately in octanoic acid and then mixed prior to drop-casting onto a HOPG surface at room temperature; ii) after drop-casting of the mixture onto HOPG, the condensation reaction between monomers was carried out in a vacuum oven at $140^{\circ} \mathrm{C}$ with a base pressure of $<133 \mathrm{~Pa}$; iii) the monomers have been deposited on the top of a warm HOPG surface.

STM images of the polymers obtained via on-surface condensation between compound 6 and aromatic diamines 27, 28 and 34 at the solid/liquid interface revealed the formation of highly ordered arrays of 1D polymers (Figure 9). The dense packing of the 1D polymers chains is stabilized by side-by-side van der Waals interaction between the polymeric backbones. However, as a result of co-condensation reaction between $\mathbf{6}$ and $\mathbf{3 4}$, also loosely packed structure are formed, as evident in Figure 9c (marked with the red arrow). Such observation has been attributed to the repulsion between polymer chains. After changing aldehyde 6 to 7, Schiff-base reaction between 7 with 27 and 28 resulted in highly ordered 1D polymers. The STM imaging of 1DIPs prepared via thermal-annealing the samples at $140^{\circ} \mathrm{C}$ in a vacuum oven sample after deposition did not reveal any significant differences with respect to samples prepared at the solid/liquid interface, suggesting that the reaction occurs at room temperature and further annealing does enhance the degree of polymerization. Noteworthy, for the co-condensation of $\mathbf{7}$ and $\mathbf{2 8}$, the reactions carried at lower concentration $\left(1.6 \times 10^{-5} \mathrm{~mol} / \mathrm{L}\right)$ yielded the same pattern observed at higher ones $(1.6$ $\left.x 10^{-4} \mathrm{~mol} / \mathrm{L}\right),{ }^{[80]}$ while co-condensation of 7 with 34 at low concentration $\left(1.4 \times 10^{-4} \mathrm{~mol} / \mathrm{L}\right)$ resulted in the formation of disordered polymers. ${ }^{[82]}$ The absence of close-packed domains was ascribed to the conformational disorder brought into play by the octyl chains. Interestingly, as a result of condensation reaction of dialdehyde $\mathbf{5}$ with $\mathbf{2 7}, \mathbf{2 8}$ and 34, zig-zag polymers are produced. 


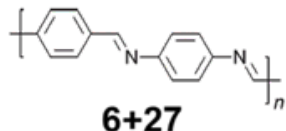

$6+27$

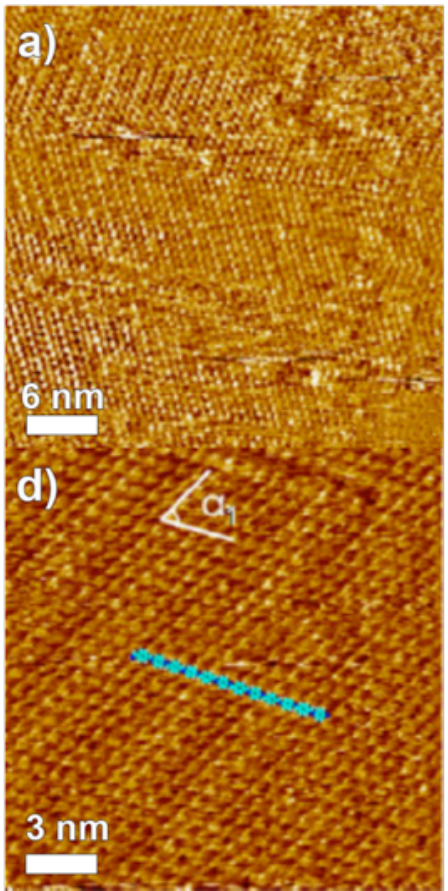

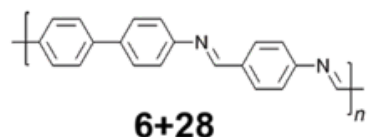

$6+28$

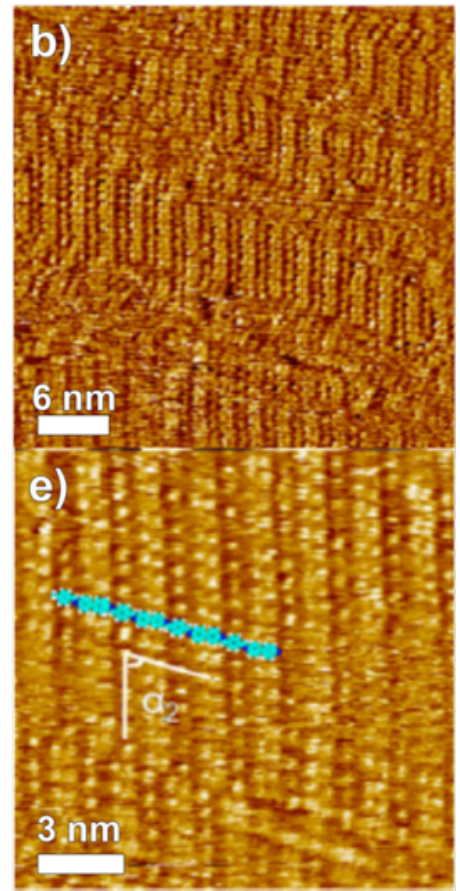

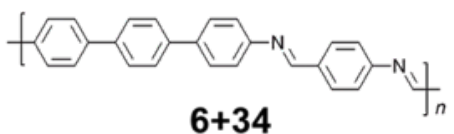

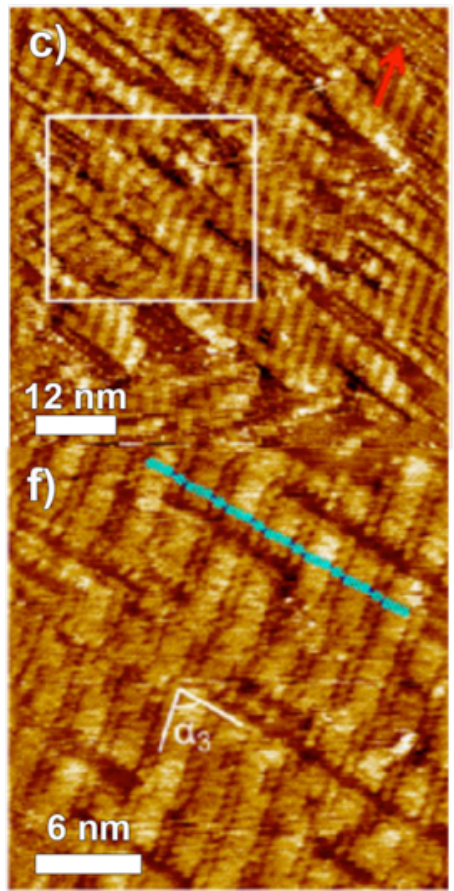

Figure 9. Typical $(a-c)$ wide-area and $(d-f)$ molecular-resolution STM images of highly ordered monolayers of linear 1D $\pi$-conjugated polymers formed at the octanoic acid/HOPG interface. Imaging conditions: (a) $I_{t}=17 \mathrm{pA}$, $V_{t}=0.50 \mathrm{~V} ;(\mathrm{b}) \mathrm{I}_{\mathrm{t}}=21 \mathrm{pA}, \mathrm{V}_{\mathrm{t}}=0.56 \mathrm{~V}$, (c) $\mathrm{I}_{\mathrm{t}}=33 \mathrm{pA}, \mathrm{V}_{\mathrm{t}}=0.50 \mathrm{~V} ;$ (d) $\mathrm{I}_{\mathrm{t}}=24 \mathrm{pA}, \mathrm{V}_{\mathrm{t}}=0.63 \mathrm{~V} ;$ (e) $\mathrm{I}_{\mathrm{t}}=21 \mathrm{pA}, \mathrm{V}_{\mathrm{t}}=$ $0.77 \mathrm{~V}$; (f) $\mathrm{I}_{\mathrm{t}}=49 \mathrm{pA}, \mathrm{V}_{\mathrm{t}}=0.50 \mathrm{~V}$. Reproduced from Ref., ${ }^{[82]}$ with permissions of the American Chemical Society.

Interestingly, it has been also demonstrated that 1D polymer can be obtained from self-assembled bi-component arrays of 7 and $35 .{ }^{[81]}$ In particular, the use of quinone - an $n$ type molecule is extremely interesting from the electronic viewpoint, as it can be used to modulate the electronic properties of 1D polymers. The deposition a mixture of 7 and 35 on the HOPG surface with the molar ratio 1:1, lead to the formation of well-defined 2D networks. These networks consist of supramolecular assembly of $\mathbf{7}$ and $\mathbf{3 5}$, and are laterally stabilized by the $\mathrm{N}-\mathrm{H} \cdots \mathrm{O}$ hydrogen bonds between the amino and quinone or aldehyde groups. Interestingly, after $75 \mathrm{~min}$, the two-dimensional network rearranges into more disordered and compact structure attributed to 1DIP. Noteworthy, similar results can be obtained by annealing existing bi-component arrays of 7 and 35 at $100^{\circ} \mathrm{C}$, which accelerates the condensation between the monomers and promotes the formation of 1DIPs.

Schiff-base coupling can be controlled also by changing the $\mathrm{pH}$ of aqueous solutions. At low $\mathrm{pH}$ values most of the amino groups exist in their positively charged ammonium form $\left(-\mathrm{NH}_{3}{ }^{+}\right)$and they do not react with the aldehydes, while by rising the $\mathrm{pH}$, the ammonium ions get deprotonated to $-\mathrm{NH}_{2}$ and can react with aldehydes to form Schiff bases via nucleophilic addition at the aldehyde. ${ }^{[83]}$ Terephthalaldehyde (6) and 4,4'-diaminostilbene (32) have been used as monomers $\pi$-conjugated $1 \mathrm{D}$ polymers on iodine-modified Au(111) surface. ${ }^{[83]}$ The 
$\mathrm{pH}$ of solutions containing monomers was adjusted with $\mathrm{HCl}$ or $\mathrm{NaOH}$. STM investigation of the samples prepared by drop-casting the aqueous mixture of 6 and 32 at $\mathrm{pH} 2.1$ and 3.6 revealed the existence of ordered $1 \mathrm{D}$ polymers. In aqueous solutions, at $\mathrm{pH}$ values below 1.5 all amino groups of $\mathbf{3 2}$ are protonated, i.e. they exist as ammonium ions $\left(32^{2+}\right)$. Upon increasing $\mathrm{pH}, \mathbf{3 2}$ gradually deprotonates to $32^{\circ}$ and above $\mathrm{pH} 5.532$ exist in its amino form, whereas on $\mathrm{I} / \mathrm{Au}(111)$ surface, 32 behaves quite differently. At $\mathrm{pH} 1.0$, the majority of 32 molecules are deprotonated to $\mathbf{3 2}^{\circ}$, while at $\mathrm{pH} 4.0$ nearly all $\mathbf{3 2}$ molecules are in their amino state. This was ascribed to the competition between solvation and adsorption of 32 . The solvation of deprotonated $\mathbf{3 2}$ on $\mathrm{I} / \mathrm{Au}(111)$ is lower than $\mathbf{3 2 ^ { 2 + }}$, and the adsorption of $\mathbf{3 2} \mathbf{2}^{\mathrm{C}}$ is favored on the $\mathrm{I} / \mathrm{Au}(111)$ surface and it leads to improved formation of m-conjugated $1 \mathrm{D}$ polymers on I/Au(111) surface. Moreover, iodine-modified Au(111) surface withdraws water molecules, which changes the equilibrium of reaction toward formation of polymers.

Tanoue and co-workers carried out Schiff-base reactions of diamines 27, 32 and 33 with aromatic dialdehydes 4, 5, 6, 12 and $13 .{ }^{[84]}$ They found that the yield of the reactions increases with the $\mathrm{pK}_{\mathrm{a}}$ of the amine, a result that can be also explained in difference of the electronic density of the amine units. The chemical structures of diamines and dialdehydes, and in particular, the substitution positions of the benzene ring have a significant influence on their reactivity during Schiff-base reactions. Based on experimental results, the reactivity of three investigated diamines has been estimated as $32>27>33$. The results of condensation between various diamines and dialdehydes are reported in Table 1. 
Table 1. Summary of the results of Schiff-base reactions of different combinations of aromatic diamine-dialdehyde molecules in homogeneous media and onto surface ("-" - not measured). Reproduced from Ref., ${ }^{[84]}$ with permissions of American Chemical Society.

\begin{tabular}{|c|c|c|c|c|c|c|}
\hline Amine & \multicolumn{2}{|c|}{$27(\mathrm{pKa}=2.9,6.0)$} & \multicolumn{2}{|c|}{$32(\mathrm{pKa}=2.9)$} & \multicolumn{2}{|c|}{$33(\mathrm{pKa}=2.1,3.9)$} \\
\hline Conditions & $\begin{array}{c}\text { In } \\
\text { homogenous } \\
\text { media (at } \mathrm{pH})\end{array}$ & $\begin{array}{c}\text { Monolayer } \\
\text { on I/Au(111) } \\
(\text { at } \mathrm{pH})\end{array}$ & $\begin{array}{c}\text { In } \\
\text { homogenous } \\
\text { media (at } \\
\text { pH) } \\
\end{array}$ & $\begin{array}{c}\text { Monolayer } \\
\text { on I/Au(111) } \\
(\text { at } \mathrm{pH})\end{array}$ & $\begin{array}{c}\text { In } \\
\text { homogenous } \\
\text { media (at } \mathrm{pH})\end{array}$ & $\begin{array}{c}\text { Monolayer } \\
\text { on I/Au(111) } \\
(\text { at } \mathrm{pH})\end{array}$ \\
\hline 4 & $\begin{array}{l}\text { Dispersion of } \\
\text { dimeric } \\
\text { product (3.5) }\end{array}$ & $\begin{array}{l}\text { Disordered } \\
\text { adlayer of } \\
\text { dimeric } \\
\text { product }\end{array}$ & 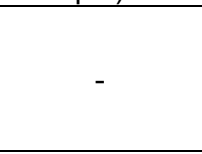 & - & - & - \\
\hline 5 & $\begin{array}{c}\text { Oligomeric } \\
\text { sedimentation } \\
(3.5)\end{array}$ & $\begin{array}{c}\text { Zig-zag } \\
\text { array (3.5) }\end{array}$ & - & - & $\begin{array}{c}\text { Oligomeric } \\
\text { sedimentation } \\
(6.0)\end{array}$ & $\begin{array}{l}\text { Indistinct, } \\
\text { but layer } \\
\text { exists }(6.0)\end{array}$ \\
\hline 6 & $\begin{array}{c}\text { Oligomeric } \\
\text { sedimentation } \\
(3.5)\end{array}$ & $\begin{array}{c}\text { Ordered } \\
\text { array }(2.5- \\
3.0)\end{array}$ & $\begin{array}{l}\text { Not reacted } \\
(2.3-6.0)\end{array}$ & $\begin{array}{c}\text { Ordered } \\
\text { array (3.0) }\end{array}$ & $\begin{array}{c}\text { Not reacted } \\
(4.0) \\
\text { Oligomeric } \\
\text { sedimentation } \\
(6.0-7.5)\end{array}$ & $\begin{array}{c}\text { Ordered } \\
\text { array (2.5) }\end{array}$ \\
\hline 12 & $\begin{array}{c}\text { Oligomeric } \\
\text { sedimentation } \\
(3.5) \\
\end{array}$ & $\begin{array}{c}\text { Ordered } \\
\text { array (2.5) }\end{array}$ & Not reacted & $\begin{array}{c}\text { Disordered } \\
\text { adlayer (2.5) }\end{array}$ & $\begin{array}{c}\text { Oligomeric } \\
\text { sedimentation } \\
(6.0)\end{array}$ & $\begin{array}{c}\text { Ordered } \\
\text { array (5.0) }\end{array}$ \\
\hline 13 & - & $\begin{array}{l}\text { Disordered } \\
\text { array (3.0) }\end{array}$ & - & $\begin{array}{l}\text { Indistinct, } \\
\text { but layer } \\
\text { exists (3.0) }\end{array}$ & - & - \\
\hline
\end{tabular}

Reactions of $\mathbf{3 2}$ with dialdehydes in solution are thermodynamically favored at $\mathrm{pH}>$ $\mathrm{pK}_{\mathrm{a}}$ of the amine and precipitate of polycondensation products are observed with all investigated dialdehydes, except 4 . In case of $\mathbf{2 7}$, which possess two distinct $\mathrm{pK}_{\mathrm{a}}$ values, i.e. $\mathrm{pK}_{\mathrm{a} 1}$ and $\mathrm{pK}_{\mathrm{a} 2}$, which refer to the first and second deprotonation reaction, respectively, for polyprotonic acids, the precipitate of products in homogenous aqueous solution is formed at $\mathrm{pH}$ values higher than $\mathrm{pK}_{\mathrm{a} 2}$. However, between $\mathrm{pK}_{\mathrm{a} 1}$ and $\mathrm{pK}_{\mathrm{a} 2}$, soluble oligomeric products are obtained, while for $\mathbf{3 3}$, the values of $\mathrm{pK}_{\mathrm{a} 1}$ and $\mathrm{pK}_{\mathrm{a} 2}$ are lower than $\mathbf{2 7}$ and no precipitate was observed in solution at $\mathrm{pH}$ region for low concentration. Remarkably, when the polycondensation reaction takes place on a hydrophobic surface such as iodine-modified $\mathrm{Au}(111)$, the 1D polymers can be formed at $\mathrm{pH}$ lower than the $\mathrm{pK}_{\mathrm{a}}$, since the reactions are accelerated by the presence of the surface, i.e. dynamic adsorption/desorption process, which confines the dimensionality of the reaction from 3D to 2D.

Recently, Yu and co-workers have systematically investigated the effect of substrate surface on the selectivity toward specific products from a multi-component dynamic covalent library, as well as the transimination occurring in 1D polymer at the solid/liquid interface. ${ }^{[80]}$ In particular, an equimolar solution of $\mathbf{2 8}$ and $\mathbf{3 7}$ was deposited on a pre-existing monolayer of 1DIP generated through condensation of 7 with 28 and 7 with $\mathbf{3 7}$. When a solution of $\mathbf{3 7}$ was 
applied on top of the 1DIP 7+28, a new 1D polymer-based pattern, i.e. $\mathbf{7 + 3 7}$ was generated. Nevertheless, after $3 \mathrm{~h}$, STM imaging revealed the co-existence of both polymers, i.e. $\mathbf{7 + 2 8}$ and $7+37$ on the surface, thereby highlighting highly dynamic nature of $1 \mathrm{D}$ polymers. Noteworthy, when the transimination occurs in the middle of $1 \mathrm{D}$ polymer chain, a structural defect appears as a result of a mismatch in the backbone (diamine) length. Nevertheless, after annealing the sample at $100^{\circ} \mathrm{C}$ for 30 minutes, which promotes self-healing of $1 \mathrm{D}$ polymers, and in general increases the dynamics of molecules adsorbed on solid substrates, only $1 \mathrm{D}$ polymer $\mathbf{7 + 3 7}$ was monitored.

\subsection{D COVALENT ORGANIC FRAMEWORKS}

In recent years, the synthesis of covalent organic frameworks (COFs) has attracted significant attention as they can be seen as synthetic analogues of naturally occurring twodimensional layered materials (2DLMs) such as graphene or $\mathrm{MoS}_{2}$. The on-surface synthesis of 2D COFs on solid surfaces has been successfully demonstrated both under UHV ${ }^{[85-87]}$ and under ambient conditions, ${ }^{[53,88-89]}$ allowing the generation of 2D polymers with single-layer thickness. ${ }^{[90-92]}$ Typically, 2D or 3D COFs are obtained through formation of covalent bonds between molecular building blocks, which allows fine-tuning of their properties, and enables a precise control over composition, topology and porosity. ${ }^{[93-94]}$ By choosing the suitable building blocks and appropriate synthetic protocols, it is possible to confine the dimensionality of materials to $2 \mathrm{D} .^{[95-97]}$

Similarly to graphene or other 2DLMs, 2D COFs sheets have a tendency to form layered structures in which the sheets interact via van der Waals forces. Such superstructures are appealing for technologically relevant applications, e.g. energy storage and charge transport. In particular, COFs based on 2D $\pi$-conjugated structures, are extremely interesting. The bottom-up programmability of their chemical structure opens a wealth of intriguing perspectives for the tuning of their properties with an atomic precision. In this way one can tailor $2 \mathrm{D}$ materials with unique electronic characteristics ${ }^{[98]}$ for (photo-) electronic applications. ${ }^{[58,99-102]}$ Moreover, functionalized 2D COFs hold the potential to serve as a chelating agent, and therefore can be used in preparation of a molecular-scale membranes with well-ordered recognition sites toward metal ions, which could find applications in sensing ${ }^{[103]}$ or catalysis. ${ }^{[99,104-105]}$

Various type of 2D COFs have been obtained via on-surface synthesis through different types of reactions, e.g. polycondensation involving boronic acid derivatives ${ }^{[106-108]}$ or Schiff bases ${ }^{[71,76,88]}$, resulting in extended porous networks of high structural quality and large domain size. ${ }^{[76,106]}$ Nevertheless, despite the fact that the synthesis of $2 \mathrm{D}$ COFs on 
solid substrates is very efficient, the generation of long-range ordered $2 \mathrm{D}$ polymers with low defect density remains extremely challenging.

First attempts of in situ synthesis of 2D COFs on solid substrates were conducted on single-crystal metal substrates under UHV condition. In 2008 Weigelt and co-workers have explored two various approaches towards generation of COFs. In particular, the authors studied the condensation between an aromatic trialdehyde 17 and diamine 25 on an $\mathrm{Au}$ (111) surface (Figure 10). ${ }^{[79]}$ The first approach, which relied on the co-deposition of the monomers followed by thermal annealing above $400 \mathrm{~K}$, yielded open filamentous structures, i.e. disordered fragments of 2D COF are formed (Figure 10b). In the second approach, 17 is deposited on $\mathrm{Au}$ (111) and treated with diamine 25 under low pressure (1-5 $\times 10^{-7} \mathrm{mbar}$ ) and temperature of $120-160 \mathrm{~K}$, which led to the formation of multilayers. Subsequent thermal annealing (400-450 K) was used to trigger the occurrence of the condensation reaction. In particular, in the second method the sample with adsorbed trialdehyde 17 was heated to 400 $\mathrm{K}$ and exposed to a lower pressure $\left(5 \times 10^{-9} \mathrm{mbar}\right)$ of 25 . Representative structures resulting from the second and third method are shown in Figure 10c and d, respectively.

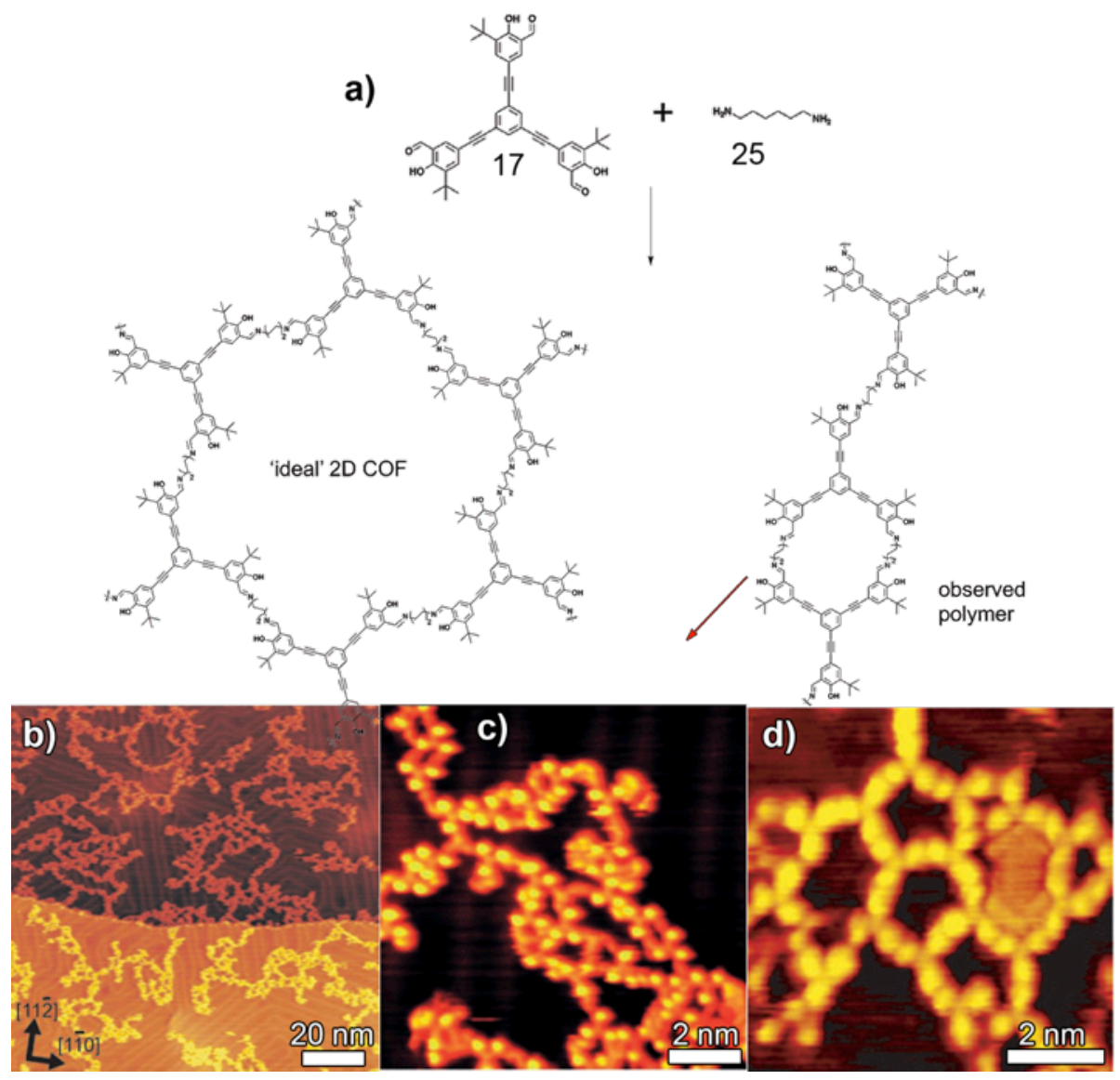

Figure 10. (a) Representative reaction of condensation polymerization of a trialdehyde 17 and diamine 25. (b) Large-scale and (c, d) small scale STM images recorded after condensation reaction shows oligomeric and macrocyclic covalent structures. Imaging conditions: (b) $I_{t}=-0.66 n A, V_{t}=-1.4 V$; (c) and (d) $I_{t}=-0.35 n A, V_{t}=-$ $1.5 \mathrm{~V}$. Reproduced from Ref., ${ }^{[79]}$ with permissions of Wiley. 
As aforementioned, the condensation between the imine precursors occurring under UHV results in low coverage and the presence of topological defects. Therefore, the use of mild reaction conditions and possibility to control the condensation between the organic molecules by tuning the parameters like concentration, $\mathrm{pH}$, solvent and temperature, have made the solid/liquid interface a particularly interesting environment for generation of $2 \mathrm{D}$ COFs, characterized by a small amount of defects and high surface coverage. ${ }^{[51,71,76,88]}$

Temperature is one of the key parameters, which enables to control of 2D arrangement; it is generally believed that thermal annealing of the sample is necessary to obtain high quality 2D COFs based on imine polymers. ${ }^{[79,88-89]}$

Triangular aldehyde 15 and linear aromatic diamines 27, 28, 30 and 34 were used by $\mathrm{Xu}$ and co-workers as precursors for the on-surface synthesis of diverse $2 \mathrm{D}$ COFs. ${ }^{[53]}$ The synthesis of 2D COFs was carried out by: i) mixing 15 with one of the diamines in octanoic acid and allowing them to condensate at room temperature at the octanoic acid/HOPG or ii) by mixing the monomers in dimethylsulfoxide (DMSO) and polymerizing them on HOPG with moderate heating $\left(140^{\circ} \mathrm{C}\right.$ for ca. $\left.30 \mathrm{~min}\right)$. Furthermore, low vacuum was applied to support the removal of solvent, water and unreacted monomers. This simple preparation method allowed the generation of a series of 2D COFs with tunable pore size (diameter ranging from 1.7 to $3.5 \mathrm{~nm}$ ), which can be modulated by changing the length of diamine precursors.

The same approach has been recently exploited for tailoring imine-based 2D COFs with chemically active $(-\mathrm{OH})$ or chemically passive $\left(-\mathrm{OCH}_{3}\right)$ groups by mixing monomer 15 with 29 or $31^{[105]}$ Yet, the STM imaging reveled the distortion of the $-\mathrm{OH}$ functionalized $15+292 \mathrm{D} \mathrm{COF}$, which was ascribed to the further reaction of imine with the $-\mathrm{OH}$ groups activated by thermal annealing $\left(140^{\circ} \mathrm{C}\right)$.

Highly-ordered bi-component 2D COFs with honeycomb structure, can also be fabricated through self-limiting solid/vapor interface reaction method, ${ }^{[53,89,109]}$ in which the coupling reaction is tailored in order to take place at the solid-vapor interface by introducing one precursor via vaporization to the surface preloaded with the other precursor. In particular, the condensation between monomers 6 and 38 or 15 and 27 was investigated by Liu and co-workers. ${ }^{[89]}$ Initially, the aldehyde (6 or 15) is applied onto a substrate by dropcasting and then the amine (38 or $\mathbf{2 7}$ ) is introduced. The whole system is then sealed and placed in the reactor containing $\mathrm{CuSO}_{4} \times 5 \mathrm{H}_{2} \mathrm{O}$ as thermodynamic regulation agent. By heating the reactor to $150^{\circ} \mathrm{C}$, the amine precursor is brought into the vapor phase and land on the surface covered with aldehyde. Subsequently, the covalent bonds are formed at the solid-vapor interface, leading to the growth of high quality 2D COF. Noteworthy, during this process, the growth of the imine-based polymer is determined by the gas phase dosing of amine, and the redundant formation of disordered oligomers is efficiently minimized. 
The porphyrin core represents a family of scaffolds possessing unique opto-electronic properties that render them interesting for various applications including catalysis ${ }^{[110-111]}$ and solar cells. ${ }^{[112-113]}$ The electronic, optical, and structural properties, as well as the solubility of porphyrins can be adjusted through chemical modifications with different metal centers or various substituents. The aforementioned properties in the combination with the structural features (planar geometry) ${ }^{[67,114-117]}$ make the porphyrin a superior candidate for its use for the generation of 2D COFs. ${ }^{[88,109,118]}$

Sun and co-workers have investigated the on-surface reaction between 5,10,15,20meso-tetra(4-aminophenyl)porphine (42) and three dialdehydes, i.e. 6, 7 and 14 on HOPG surface. ${ }^{[118]}$ The synthesis of $2 \mathrm{D}$ COF $\mathbf{7 + 4 2}$ was conducted by applying a mixture of monomers onto the surface and subsequent annealing at $200^{\circ} \mathrm{C}$ for 30 minutes. The STM investigation revealed the existence of small 2D COF domains featuring a square lattice, which do not show any preferential orientation along with the major symmetry axes of graphite surface. Moreover, the presence of condensation side products, i.e. 1DIP chains, was monitored (marked white arrow in Figure 11b). In the high-resolution STM image (Figure 11c), alongside from squared structures, also rhombus architectures (black arrow) can also be observed. Such a polygon formation was attributed to the flexibility of the imine bond. The fine resolution of the STM image also enabled the detection of defects as highlighted by the blue arrow in Figure 11c, which was ascribed to the absence of one of diamine molecules in the $2 \mathrm{D}$ architecture. 

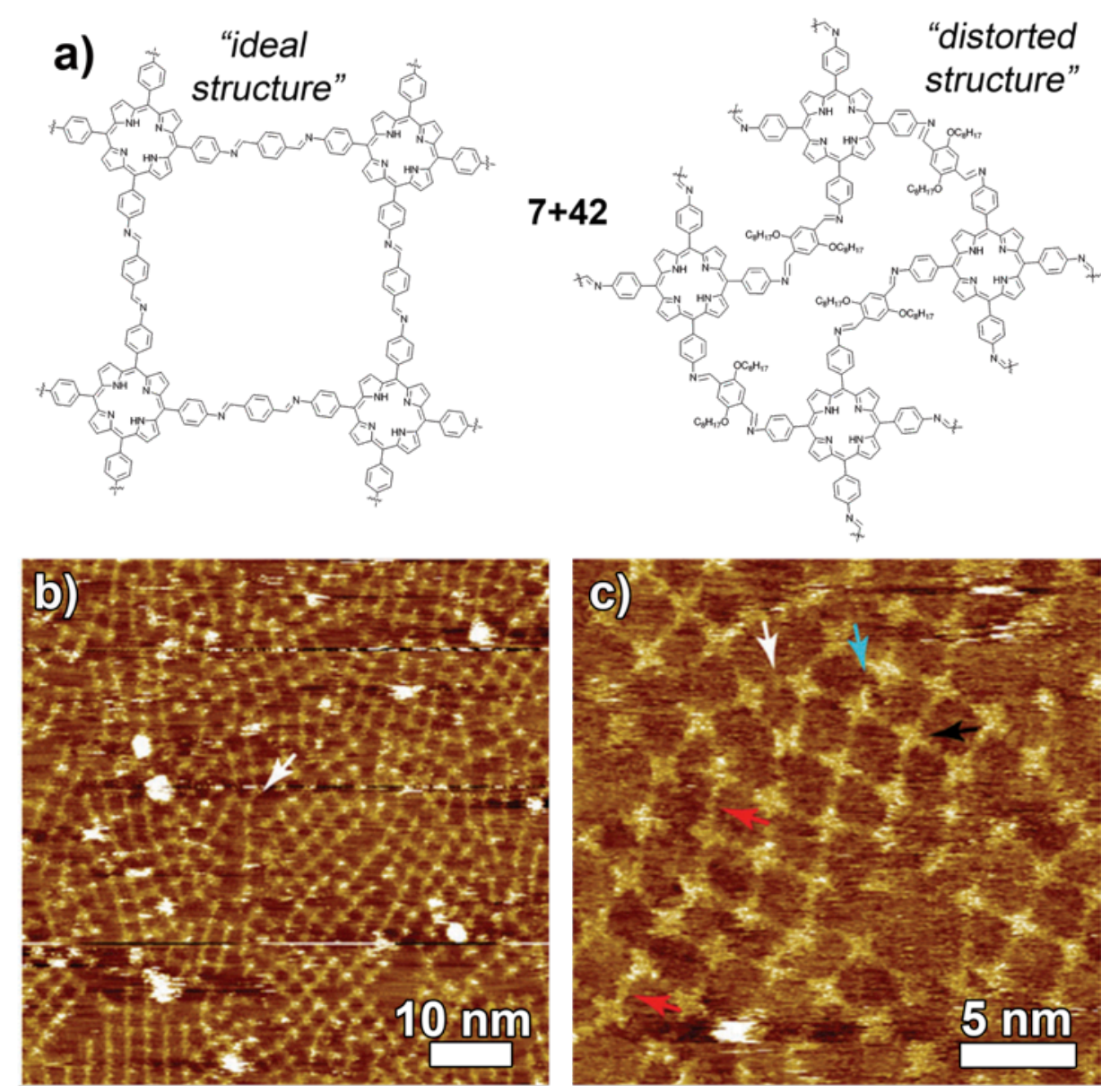

Figure 11. 2D COF generated via condensation between 7 and 42. (a) Schematic representation of COF in its two various structures, i.e. squared and distorted (rhomboidal). Large scale (b) and high-resolution (c) STM images of 2D polymer of $\mathbf{7 + 4 2}$ obtained at the air-HOPG interface. The white and black arrows in (b) indicate a triangle and a deformed square, respectively, while the blue arrow points to a site where 7 is missing. The red arrows point to two 7 linker. Imaging conditions: (b) $I_{t}=33 p A, V_{t}=300 \mathrm{mV}$; (c) $I_{t}=17 p A, V_{t}=-200 \mathrm{mV}$. Reproduced from Ref., ${ }^{[118]}$ with permissions of Royal Society of Chemistry.

According to some reports, ${ }^{[51,80,118]}$ the most important parameters ruling the formation of $2 \mathrm{D}$ COFs are the concentration and the molar ratio between the molecular building blocks. The effect of the concentration on the self-assembly of supramolecular networks based on non-covalent interactions between organic molecules has been reported nearly a decade ago, and it is now well-known phenomenon in the molecular assembly at the solid/liquid interface. ${ }^{[119-123]}$

Recently, $\mathrm{Yu}$ et al. demonstrated that the same principle also applies to the onsurface formation of 2D COFs. ${ }^{[51]}$ For co-condensation of the following monomers: 15+27, $15+28,15+34,15+37,16+34$ and 16+37, similar concentration dependent assembling behavior was observed at the solid/liquid interface, excluding that when $\mathbf{3 7}$ participates in the reaction, at high concentration, where disordered amorphous polymers were observed. Representative STM images of the 2D COFs generated at room temperature are shown in Figure 12. By keeping the molar ratio between the monomers constant, i.e. aldehyde:amine $=2: 3$, clear influence on the optimized concentration by the size of monomers was 
monitored. The optimized molar concentrations of diamines were determined as $15+27$ (2.5 $\left.\times 10^{5} \mathrm{~mol} \mathrm{~L}^{-1}\right)>\mathbf{1 5 + 2 8}\left(1.6 \times 10^{5} \mathrm{~mol} \mathrm{~L}^{-1}\right)>\mathbf{1 5 + 3 4}\left(7.4 \times 10^{6} \mathrm{~mol} \mathrm{~L}^{-1}\right)>\mathbf{1 5 + 3 7}\left(3.5 \times 10^{6} \mathrm{~mol}\right.$ $\left.\mathrm{L}^{-1}\right)$ and $16+34\left(5.3 \times 10^{6} \mathrm{~mol} \mathrm{~L}^{-1}\right)>16+37\left(2.7 \times 10^{6} \mathrm{~mol} \mathrm{~L}^{-1}\right)$. It was concluded, that for a given aldehyde, the required concentration of amine, needed to generate 2D COF, decreases with the amine length.

$15+27$

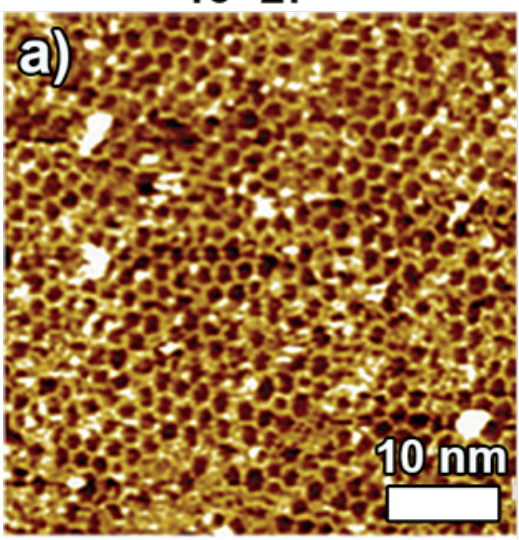

$15+37$

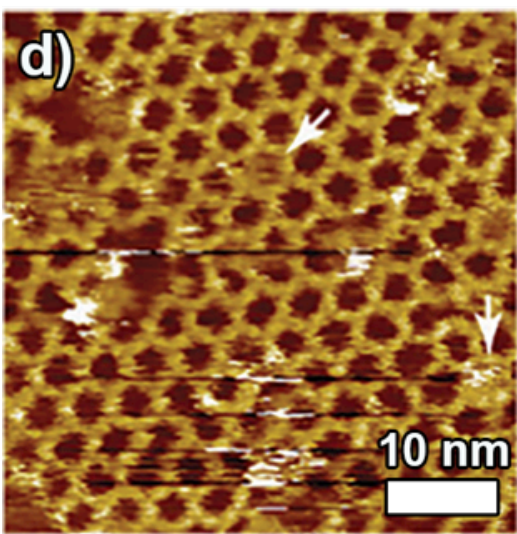

$15+28$

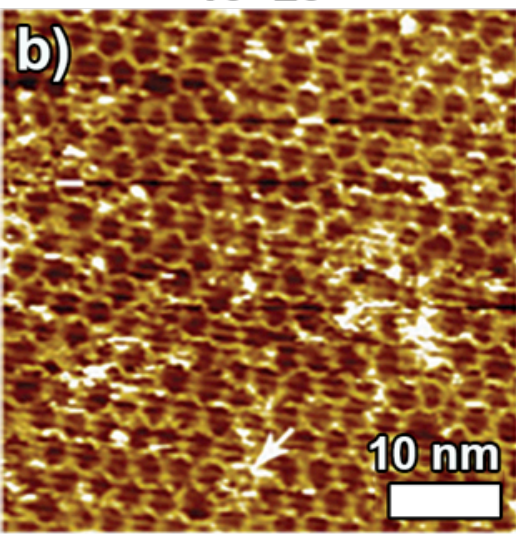

$16+34$

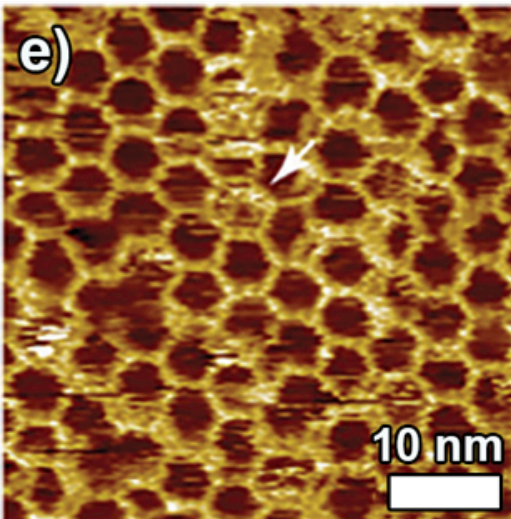

$15+34$

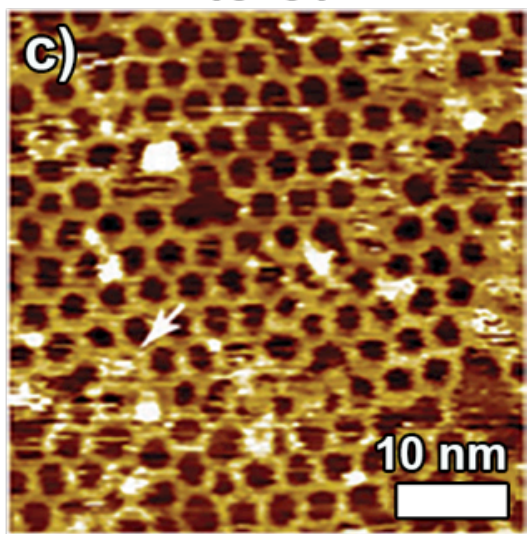

$16+37$

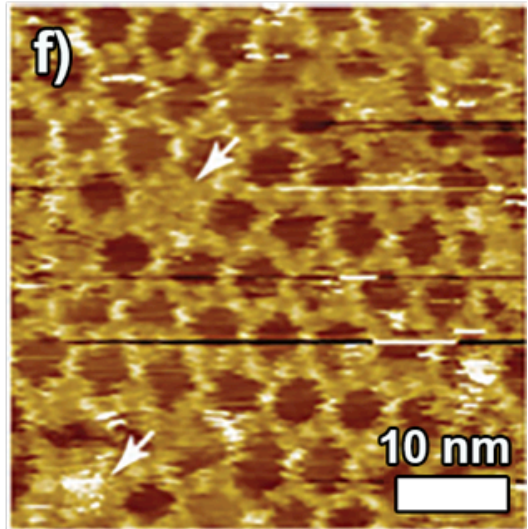

Figure 12. Representative STM images of $2 \mathrm{D}$ COFS formed at the octanoic acid/ HOPG interface. Imaging conditions: (a) $\mathrm{I}_{\mathrm{t}}=36 \mathrm{pA}, \mathrm{V}_{\mathrm{t}}=0.66 \mathrm{~V}$; (b) $\mathrm{I}_{\mathrm{t}}=53 \mathrm{pA}, \mathrm{V}_{\mathrm{t}}=0.52 \mathrm{~V}$; (c) $\mathrm{I}_{\mathrm{t}}=30 \mathrm{pA}, \mathrm{V}_{\mathrm{t}}=0.66 \mathrm{~V}$; (d) $\mathrm{I}_{\mathrm{t}}=67 \mathrm{pA}, \mathrm{V}_{\mathrm{t}}=0.80$ $\mathrm{V} ;(\mathrm{e}) \mathrm{I}_{\mathrm{t}}=30 \mathrm{pA}, \mathrm{V}_{\mathrm{t}}=0.20 \mathrm{~V}$; and (f) $\mathrm{I}_{\mathrm{t}}=30 \mathrm{pA}, \mathrm{V}_{\mathrm{t}}=1.00 \mathrm{~V}$. Reproduced from Ref., ${ }^{[51]}$ with permissions of Royal Society of Chemistry.

In 2014, Xu and co-workers demonstrated a simple method for fabricating fully aromatic 2D COF, with single atomic thickness on single-layer graphene grown by chemical vapour deposition (CVD) on copper foil. ${ }^{[1]}$ Benzene-1,3,5-tricarbaldehyde (15) and $p$ phenylene- diamine (27) were used as precursors. It is important to note that the properties of graphene are more complex than HOPG. The different facets, step edges, kinks, and other defects result in different molecule-substrate interactions with CVD graphene, and ultimately result in the change of its electronic properties. ${ }^{[124-125]}$ An extended adlayer of $\pi-$ conjugated, yet, defective structure of $15+27$ COF was observed by STM upon applying a droplet of the mixture of the two precursors to the graphene surface (Figure 13b). The in situ formation of $\mathbf{1 5 + 2 7} \mathrm{COF}$ at the solid/liquid interface can reach an equilibrium state after few 
minutes. As aforementioned, the peculiar nature of the solid/liquid interface promotes selfhealing of defects in self-assembled monolayers. Also in this case, self-healing of the defects, which can occur in the structure, may be observed in situ within ca. 1 min (Figure 13c). In Figure $13 \mathrm{~b}$ and $\mathrm{c}$, the white arrow indicates a large open pore, which was converted into a pentagon and a hexagon. The red, violet, and blue arrows highlight the healing of the $15+27$ COF surface and formation of new covalent bonds between already existing oligomers. Interestingly, the calculated band structure of $15+27$ COF shows a band gap around $2 \mathrm{eV}$, indicating that the free standing $15+27 \mathrm{COF}$ is a $2 \mathrm{D}$ organic semiconductor.
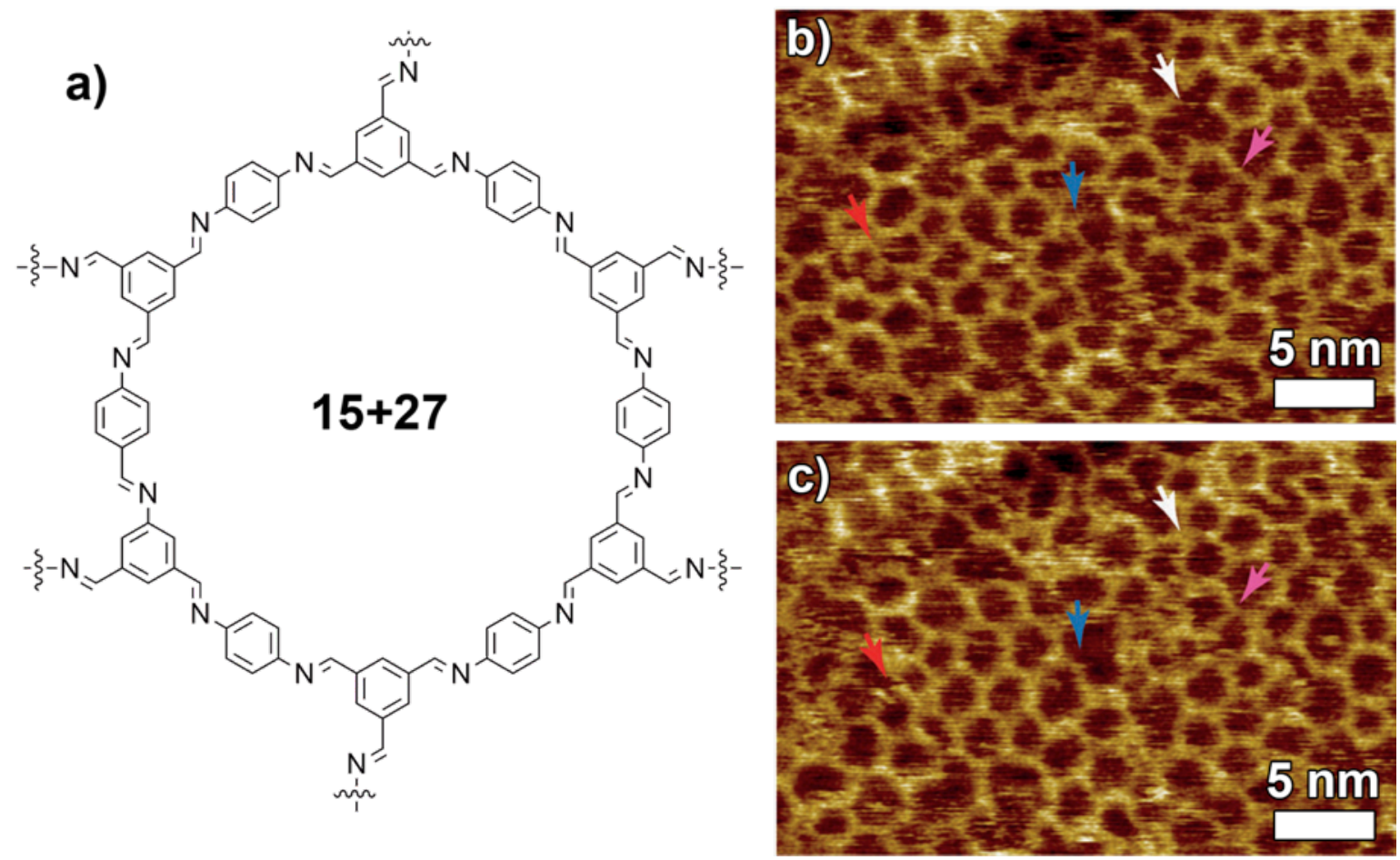

Figure 13. Formation of 2D COF $15+27$ (a) as a result of Schiff-base reaction between trialdehyde 15 and diamine 27. (b) and (c) two successive STM images showing the dynamic process of Schiff-base reaction of $15+27$ at the octanoic acid/graphene interface. The time interval is $1.08 \mathrm{~min}$. The arrows highlight the sites where noticeable changes happened. The tunneling conditions: $I_{t}=700 \mathrm{pA}, V_{t}=10 \mathrm{mV}$. (b) and (c) Reproduced from Ref., ${ }^{[91]}$ with permissions of Wiley.

\section{CONCLUSIONS AND PERSPECTIVES}

In summary, we have presented the most enlightening recent achievements in synthesis of discrete, 1D and 2D imine nanostructures via formation of covalent bonds between aldehydes and amines on atomically flat substrates, under various experimental conditions. Self-assembly at surfaces and interfaces is undoubtedly the most studied field towards the bottom-up fabrication of supramolecular structures. While many elegant imine assemblies containing 1D and 2D covalent organic frameworks have been fabricated on surfaces and interfaces, it is however clear that considerable work remains to be done. Recently, most of the on-surface synthesis of imine-based nanostructures is conducted at 
the solid/liquid or gas/solid interface, due to an uncomplicated infrastructure and mild reaction conditions, which enable full control by external and internal stimuli, such as temperature, concentration, $\mathrm{pH}$, solvent, etc., leading to the formation of more ordered structure, if compared to reactions performed under UHV condition. The on-surface fabrication of well-defined $1 \mathrm{D}$ and $2 \mathrm{D}$ imine-based conjugated polymers offers paths to the preparation of films with a specific thickness and a well-defined structure without the need of thermal annealing. In case of surface 2D COFs, it is possible to modify their electronic structure (by introducing substituents in desired positions with an atomic precision) or the pore size (by varying the length of the monomers). Moreover, both $1 \mathrm{D}$ and $2 \mathrm{D}$ COFs supported on solid substrates may serve as templates for the growth of 3D COFs with novel structural motifs thus functions. These results open the doors for bottom-up assembly of a vast array of solid-supported, designer DCC nanoarchitectures with potential application in low cost, flexible devices, electronics, solar and fuel cells, chemical and biosensors, heterocatalysis, inkjet printing, separations, nanoporous membranes, and commercial coatings. ${ }^{[7]}$

Nevertheless, as the formation of 1D and 2D COFs on solid substrates is only based on the STM imaging, further multiscale investigation (in time and space) on the chemical composition, structure and function is needed to provide unambiguous evidence of the imine formation. Functional groups that involve a $\mathrm{C}=\mathrm{N}$ unit, such as imines are of special interest because they may undergo disconnection/reconnection cycles. Reversibility is an important feature of the $\mathrm{C}=\mathrm{N}$ linkage. Imines are widely exploited by nature in many enzymatic processes and by organic chemists in a variety of applications, mostly due to the reversibility of the reactions under thermodynamic equilibrium. The introduction of different polar and non-polar groups to the backbone of constructed networks, which can influence pore size, polarity and reactivity may reveal the real potential of these covalent, yet, reversible type of functional materials.

\section{ACKNOWLEDGMENTS}

This work was supported by the Polish National Science Centre (Grant no. 2015/18/E/ST5/00188). We also are thankful for the support of the Agence Nationale de la Recherche through the LabEx project Chemistry of Complex Systems (ANR-10-LABX0026_CSC), the International Center for Frontier Research in Chemistry (icFRC). 


\section{REFERENCES}

[1] S. J. Rowan, S. J. Cantrill, G. R. L. Cousins, J. K. M. Sanders, J. F. Stoddart, Angew. Chem. Int. Ed. 2002, 41, 898-952.

[2] Y. H. Jin, C. Yu, R. J. Denman, W. Zhang, Chem. Soc. Rev. 2013, 42, 6634-6654.

[3] J.-M. Lehn, Chem. Eur. J. 1999, 5, 2455-2463.

[4] P. T. Corbett, J. Leclaire, L. Vial, K. R. West, J. L. Wietor, J. K. M. Sanders, S. Otto, Chem. Rev. 2006, 106, 3652-3711.

[5] B. L. Miller, in Dynamic Combinatorial Chemistry in Drug Discovery, Bioorganic Chemistry, and Materials Science, John Wiley \& Sons, Inc., 2009, pp. 1-42.

[6] W. Zhang, Y. Jin, Dynamic Covalent Chemistry: Principles, Reactions, and Applications, Wiley, 2017.

[7] J. L. Segura, M. J. Mancheno, F. Zamora, Chem. Soc. Rev. 2016, 45, 5635-5671.

[8] C. S. Diercks, O. M. Yaghi, Science 2017, 355, 923-931.

[9] T. Maeda, H. Otsuka, A. Takahara, Prog. Polym. Sci. 2009, 34, 581-604.

[10] J. Elemans, Adv. Funct. Mater. 2016, 26, 8932-8951.

[11] A. Herrmann, Chem. Soc. Rev. 2014, 43, 1899-1933.

[12] F. Klepel, B. J. Ravoo, Org. Biomol. Chem. 2017, 15, 3840-3842.

[13] S. P. Black, J. K. M. Sanders, A. R. Stefankiewicz, Chem. Soc. Rev. 2014, 43, 18611872.

[14] B. Fuchs, A. Nelson, A. Star, J. F. Stoddart, S. B. Vidal, Angew. Chem. Int. Ed. 2003, 42, 4220-4224.

[15] R. Cacciapaglia, S. Di Stefano, L. Mandolini, J. Am. Chem. Soc. 2005, 127, $13666-$ 13671.

[16] R. C. Brachvogel, M. von Delius, Eur. J. Org. Chem. 2016, 3662-3670.

[17] G. Kaiser, J. K. M. Sanders, Chem. Commun. 2000, 1763-1764.

[18] W. X. Liu, C. Zhang, H. Zhang, N. Zhao, Z. X. Yu, J. Xu, J. Am. Chem. Soc. 2017, 139, 8678-8684.

[19] A. L. Korich, P. M. lovine, Dalton Trans. 2010, 39, 1423-1431.

[20] A. P. Côté, A. I. Benin, N. W. Ockwig, M. O'Keeffe, A. J. Matzger, O. M. Yaghi, Science 2005, 310, 1166-1170.

[21] Y. Jin, Q. Wang, P. Taynton, W. Zhang, Acc. Chem. Res. 2014, 47, 1575-1586.

[22] M. E. Belowich, J. F. Stoddart, Chem. Soc. Rev. 2012, 41, 2003-2024.

[23] E. H. Cordes, W. P. Jencks, J. Am. Chem. Soc. 1962, 84, 832-837.

[24] R. W. Layer, Chem. Rev. 1963, 63, 489-510.

[25] S. Dayagi, Y. Degani, in Carbon-Nitrogen Double Bonds (Ed.: S. Panai), Wiley, 2010, pp. 61-147.

[26] L. Tauk, A. P. Schroder, G. Decher, N. Giuseppone, Nat. Chem. 2009, 1, 649-656.

[27] R. Bonnett, in Carbon-Nitrogen Double Bonds (1970) (Ed.: S. Patai), Wiley, 2010, pp. 597-662.

[28] H. Sahabudeen, H. Qi, B. A. Glatz, D. Tranca, R. Dong, Y. Hou, T. Zhang, C. Kuttner, T. Lehnert, G. Seifert, U. Kaiser, A. Fery, Z. Zheng, X. Feng, Nat. Commun. 2016, 7 , 13461.

[29] W. Dai, F. Shao, J. Szczerbiński, R. McCaffrey, R. Zenobi, Y. Jin, A. D. Schlüter, W. Zhang, Angew. Chem. Int. Ed. 2016, 55, 213-217.

[30] M. C. T. Fyfe, J. F. Stoddart, Acc. Chem. Res. 1997, 30, 393-401.

[31] J.-M. Lehn, Chem. Soc. Rev. 2007, 36, 151-160.

[32] J.-M. Lehn, in Constitutional Dynamic Chemistry (Ed.: M. Barboiu), Springer Berlin Heidelberg, Berlin, Heidelberg, 2012, pp. 1-32.

[33] M. Ciaccia, R. Cacciapaglia, P. Mencarelli, L. Mandolini, S. Di Stefano, Chem. Sci. 2013, 4, 2253-2261.

[34] F. J. Uribe-Romo, J. R. Hunt, H. Furukawa, C. Klöck, M. O’Keeffe, O. M. Yaghi, J. Am. Chem. Soc. 2009, 131, 4570-4571.

[35] J. P. Rabe, S. Buchholz, Science 1991, 253, 424-427. 
[36] S. De Feyter, A. Gesquière, M. M. Abdel-Mottaleb, P. C. M. Grim, F. C. De Schryver, C. Meiners, M. Sieffert, S. Valiyaveettil, K. Müllen, Acc. Chem. Res. 2000, 33, 520531.

[37] A. M. Jackson, J. W. Myerson, F. Stellacci, Nat Mater 2004, 3, 330-336.

[38] A. Cadeddu, A. Ciesielski, T. El Malah, S. Hecht, P. Samorì, Chem. Commun. 2011, 47, 10578-10580.

[39] A. Ciesielski, A. Cadeddu, C.-A. Palma, A. Gorczyński, V. Patroniak, M. Cecchini, P. Samorì, Nanoscale 2011, 3, 4125-4129.

[40] J. M. MacLeod, O. Ivasenko, D. F. Perepichka, F. Rosei, Nanotechnology 2007, 18, 424031.

[41] A. Ciesielski, G. Schaeffer, A. Petitjean, J.-M. Lehn, P. Samorì, Angew. Chem. Int. Ed. 2009, 121, 2073-2077.

[42] A. Ciesielski, L. Piot, P. Samorì, A. Jouaiti, M. W. Hosseini, Adv. Mater. 2009, 21, $1131-1136$.

[43] A. Ciesielski, P. Samorì, Nanoscale 2011, 3, 1397-1410.

[44] M. E. Cañas-Ventura, W. Xiao, D. Wasserfallen, K. Müllen, H. Brune, J. V. Barth, R. Fasel, Angew. Chem. Int. Ed. 2007, 46, 1814-1818.

[45] S. Stepanow, M. Lingenfelder, A. Dmitriev, H. Spillmann, E. Delvigne, N. Lin, X. Deng, C. Cai, J. V. Barth, K. Kern, Nat Mater 2004, 3, 229-233.

[46] G. Binning, H. Rohrer, C. Gerber, E. Weibel, Phys. Rev. Lett. 1982, 49, 57-61.

[47] D. Bonifazi, S. Mohnani, A. Llanes-Pallas, Chem. Eur. J. 2009, 15, 7004-7025.

[48] A. Ciesielski, C.-A. Palma, M. Bonini, P. Samorì, Adv. Mater. 2010, 22, 3506-3520.

[49] A. Ciesielski, M. El Garah, S. Masiero, P. Samorì, Small 2016, 12, 83-95.

[50] L. Jiang, A. C. Papageorgiou, S. C. Oh, O. Saglam, J. Reichert, D. A. Duncan, Y. Q. Zhang, F. Klappenberger, Y. Y. Guo, F. Allegretti, S. More, R. Bhosale, A. MateoAlonso, J. V. Barth, ACS Nano 2016, 10, 1033-1041.

[51] Y. X. Yu, J. B. Lin, Y. Wang, Q. D. Zeng, S. B. Lei, Chem. Commun. 2016, 52, 66096612.

[52] L. X. Cheng, Y. B. Li, C. Y. Zhang, Z. L. Gong, Q. J. Fang, Y. W. Zhong, B. Tu, Q. D. Zeng, C. Wang, ACS Appl. Mater. Interfaces 2016, 8, 32004-32010.

[53] L. R. Xu, X. Zhou, Y. X. Yu, W. Q. Tian, J. Ma, S. B. Lei, ACS Nano 2013, 7, 80668073.

[54] Scanning Probe Microscopies Beyond Imaging: Manipulation of Molecules and Nanostructures, Ed. P. Samorì, WILEY-VCH Verlag GmbH \& Co. KGaA, Weinheim, 2006.

[55] P. Samorì, J. Mater. Chem. 2004, 14, 1353-1366.

[56] L. Grill, M. Dyer, L. Lafferentz, M. Persson, M. V. Peters, S. Hecht, Nat. Nanotechnol. 2007, 2, 687-691.

[57] B. Hulsken, R. Van Hameren, J. W. Gerritsen, T. Khoury, P. Thordarson, M. J. Crossley, A. E. Rowan, R. J. M. Nolte, J. A. A. W. Elemans, S. Speller, Nat. Nanotechnol. 2007, 2, 285-289.

[58] D. F. Perepichka, F. Rosei, Science 2009, 323, 216-217.

[59] M. Johannes, S. Sofia, P. Maike, S. Jutta, H. Stefan, G. Leonhard, J. Phys. Condens. Matter 2012, 24, 394013.

[60] D. den Boer, M. Li, T. Habets, P. lavicoli, A. E. Rowan, R. J. M. Nolte, S. Speller, D. B. Amabilino, S. De Feyter, J. A. A. W. Elemans, Nat. Chem. 2013, 5, 621.

[61] A. Ciesielski, S. Lena, S. Masiero, G. P. Spada, P. Samorì, Angew. Chem. Int. Ed. 2010, 49, 1963-1966.

[62] E. Ghijsens, O. Ivasenko, K. Tahara, H. Yamaga, S. Itano, T. Balandina, Y. Tobe, S. De Feyter, ACS Nano 2013, 7, 8031-8042.

[63] P. Samorì, K. Müllen, J. P. Rabe, Adv. Mater. 2004, 16, 1761-1765.

[64] R. Gutzler, T. Sirtl, J. F. Dienstmaier, K. Mahata, W. M. Heckl, M. Schmittel, M. Lackinger, J. Am. Chem. Soc. 2010, 132, 5084-5090.

[65] P. Vanoppen, P. C. M. Grim, M. Rucker, S. De Feyter, G. Moessner, S. Valiyaveettil, K. Müllen, F. C. De Schryver, J Phys Chem-Us 1996, 100, 19636-19641. 
[66] M. El Garah, E. Borré, A. Ciesielski, A. Dianat, R. Gutierrez, G. Cuniberti, S. Bellemin-Laponnaz, M. Mauro, P. Samorì, Small 2017, 13, 1701790.

[67] M. El Garah, A. Ciesielski, N. Marets, V. Bulach, M. W. Hosseini, P. Samorì, Chem. Commun. 2014, 50, 12250-12253.

[68] M. Surin, P. Samorì, A. Jouaiti, N. Kyritsakas, M. W. Hosseini, Angew. Chem. Int. Ed. 2007, 46, 245-249.

[69] L. Piot, R. M. Meudtner, T. El Malah, S. Hecht, P. Samorì, Chem-Eur J 2009, 15, 4788-4792.

[70] L. Piot, D. Bonifazi, P. Samorì, Adv. Funct. Mater. 2007, 17, 3689-3693.

[71] A. Ciesielski, M. El Garah, S. Haar, P. Kovaříček, J.-M. Lehn, P. Samorì, Nat. Chem. 2014, 6, 1017-1023.

[72] F. Schlütter, F. Rossel, M. Kivala, V. Enkelmann, J. P. Gisselbrecht, P. Ruffieux, R. Fasel, K. Müllen, J. Am. Chem. Soc. 2013, 135, 4550-4557.

[73] S. Weigelt, C. Busse, C. Bombis, M. M. Knudsen, K. V. Gothelf, T. Strunskus, C. Woll, M. Dahlbom, B. Hammer, E. Laegsgaard, F. Besenbacher, T. R. Linderoth, Angew. Chem. Int. Ed. 2007, 46, 9227-9230.

[74] Y. B. Li, J. H. Wan, K. Deng, X. N. Han, S. B. Lei, Y. L. Yang, Q. Y. Zheng, Q. D. Zeng, C. Wang, J. Phys. Chem. C 2011, 115, 6540-6544.

[75] J. Plas, D. Waghray, J. Adisoejoso, O. Ivasenko, W. Dehaen, S. De Feyter, Chem. Commun. 2015, 51, 16338-16341.

[76] F. Y. Hu, X. M. Zhang, X. C. Wang, S. Wang, H. Q. Wang, W. B. Duan, Q. D. Zeng, C. Wang, ACS Appl. Mater. Interfaces 2013, 5, 1583-1587.

[77] J. Y. Yue, M. Markoulides, A. C. Regan, S. Y. Li, N. Chronakis, A. Gourdon, T. Chen, H. J. Yan, D. Wang, Chem. Commun. 2017, 53, 428-431.

[78] J. Sun, Y. X. Yu, C. H. Liu, S. B. Lei, J. Phys. Chem. C 2017, 121, 3437-3444.

[79] S. Weigelt, C. Busse, C. Bombis, M. M. Knudsen, K. V. Gothelf, E. Laegsgaard, F. Besenbacher, T. R. Linderoth, Angew. Chem. Int. Ed. 2008, 47, 4406-4410.

[80] Y. X. Yu, J. B. Lin, S. B. Lei, RSC Adv. 2017, 7, 11496-11502.

[81] Y. X. Yu, Y. L. Zheng, S. B. Lei, J. Phys. Chem. C 2017, 121, 593-599.

[82] Y. X. Yu, J. Sun, S. B. Lei, J. Phys. Chem. C 2015, 119, 16777-16784.

[83] M. Di Giovannantonio, T. Kosmala, B. Bonanni, G. Serrano, N. Zema, S. Turchini, D. Catone, K. Wandelt, D. Pasini, G. Contini, C. Goletti, J. Phys. Chem. C 2015, 119, 19228-19235.

[84] R. Tanoue, R. Higuchi, K. Ikebe, S. Uemura, N. Kimizuka, A. Z. Stieg, J. K. Gimzewski, M. Kunitake, Langmuir 2012, 28, 13844-13851.

[85] N. A. A. Zwaneveld, R. Pawlak, M. Abel, D. Catalin, D. Gigmes, D. Bertin, L. Porte, J. Am. Chem. Soc. 2008, 130, 6678-6679.

[86] L. Lafferentz, V. Eberhardt, C. Dri, C. Africh, G. Comelli, F. Esch, S. Hecht, L. Grill, Nat. Chem. 2012, 4, 215-220.

[87] J. Eichhorn, T. Strunskus, A. Rastgoo-Lahrood, D. Samanta, M. Schmittel, M. Lackinger, Chem. Commun. 2014, 50, 7680-7682.

[88] R. Tanoue, R. Higuchi, N. Enoki, Y. Miyasato, S. Uemura, N. Kimizuka, A. Z. Stieg, J. K. Gimzewski, M. Kunitake, ACS Nano 2011, 5, 3923-3929.

[89] X. H. Liu, C. Z. Guan, S. Y. Ding, W. Wang, H. J. Yan, D. Wang, L. J. Wan, J. Am. Chem. Soc. 2013, 135, 10470-10474.

[90] M. O. Blunt, J. C. Russell, N. R. Champness, P. H. Beton, Chem. Commun. 2010, 46, 7157-7159.

[91] L. R. Xu, X. Zhou, W. Q. Tian, T. Gao, Y. F. Zhang, S. B. Lei, Z. F. Liu, Angew. Chem. Int. Ed. 2014, 53, 9564-9568.

[92] J. Sakamoto, J. van Heijst, O. Lukin, A. D. Schlüter, Angew. Chem. Int. Ed. 2009, 48, 1030-1069.

[93] A. Thomas, Angew. Chem. Int. Ed. 2010, 49, 8328-8344.

[94] Y. G. Zhang, S. N. Riduan, Chem. Soc. Rev. 2012, 41, 2083-2094.

[95] P. Zhu, V. Meunier, J. Chem. Phys. 2012, 137, 16964-16970. 
[96] L. Cardenas, R. Gutzler, J. Lipton-Duffin, C. Y. Fu, J. L. Brusso, L. E. Dinca, M. Vondracak, Y. Fagot-Revurat, D. Malterre, F. Rosei, D. F. Perepichka, Chem. Sci. 2013, 4, 3263-3268.

[97] R. Gutzler, D. F. Perepichka, J. Am. Chem. Soc. 2013, 135, 16585-16594.

[98] N. R. Champness, Nat. Nanotechnol. 2007, 2, 671-672.

[99] N. R. Champness, Nat. Chem. 2014, 6, 757-759.

[100] S. Clair, O. Ourdjini, M. Abel, L. Porte, Adv. Mater. 2012, 24, 1252-1254.

[101] S. Blankenburg, M. Bieri, R. Fasel, K. Mullen, C. A. Pignedoli, D. Passerone, Small 2010, 6, 2266-2271.

[102] J. L. Yang, D. H. Yan, T. S. Jones, Chem. Rev. 2015, 115, 5570-5603.

[103] J. Q. Liu, Z. Liu, C. J. Barrow, W. R. Yang, Anal. Chim. Acta 2015, 859, 1-19.

[104] S. Nakagaki, G. K. B. Ferreira, G. M. Ucoski, K. Castro, Molecules 2013, 18, 72797308.

[105] L. R. Xu, L. L. Cao, Z. X. Guo, Z. Q. Zha, S. B. Lei, Chem. Commun. 2015, 51, 86648667.

[106] C. Z. Guan, D. Wang, L. J. Wan, Chem. Commun. 2012, 48, 2943-2945.

[107] J. F. Dienstmaier, A. M. Gigler, A. J. Goetz, P. Knochel, T. Bein, A. Lyapin, S. Reichlmaier, W. M. Heckl, M. Lackinger, ACS Nano 2011, 5, 9737-9745.

[108] J. F. Dienstmaier, D. D. Medina, M. Dogru, P. Knochel, T. Bein, W. M. Heckl, M. Lackinger, ACS Nano 2012, 6, 7234-7242.

[109] Y. Hu, N. Goodeal, Y. Chen, A. M. Ganose, R. G. Palgrave, H. Bronstein, M. O. Blunt, Chem. Commun. 2016, 52, 9941-9944.

[110] P. Bhyrappa, J. K. Young, J. S. Moore, K. S. Suslick, J. Am. Chem. Soc. 1996, 118, 5708-5711.

[111] J. P. Collman, P. Denisevich, Y. Konai, M. Marrocco, C. Koval, F. C. Anson, J. Am. Chem. Soc. 1980, 102, 6027-6036.

[112] A. Yella, H.-W. Lee, H. N. Tsao, C. Yi, A. K. Chandiran, M. K. Nazeeruddin, E. W.-G. Diau, C.-Y. Yeh, S. M. Zakeeruddin, M. Grätzel, Science 2011, 334, 629-634.

[113] J. A. A. W. Elemans, R. van Hameren, R. J. M. Nolte, A. E. Rowan, Adv. Mater. 2006, 18, 1251-1266.

[114] J. V. Barth, G. Costantini, K. Kern, Nature 2005, 437, 671-679.

[115] S. Mohnani, D. Bonifazi, Coord. Chem. Rev. 2010, 254, 2342-2362.

[116] W. Auwärter, D. Ecija, F. Klappenberger, J. V. Barth, Nat. Chem. 2015, 7, 105-120.

[117] M. El Garah, N. Marets, M. Mauro, A. Aliprandi, S. Bonacchi, L. De Cola, A. Ciesielski, V. Bulach, M. W. Hosseini, P. Samorì, J. Am. Chem. Soc. 2015, 137, 8450-8459.

[118] X. L. Sun, L. X. Fan, X. Zhou, W. Q. Tian, Z. X. Guo, Z. B. Li, X. K. Li, S. B. Lei, Chem. Commun. 2015, 51, 5864-5867.

[119] S. Lei, K. Tahara, F. C. De Schryver, M. Van der Auweraer, Y. Tobe, S. De Feyter, Angew. Chem. Int. Ed. 2008, 47, 2964-2968.

[120] L. Kampschulte, T. L. Werblowsky, R. S. K. Kishore, M. Schmittel, W. M. Heckl, M. Lackinger, J. Am. Chem. Soc. 2008, 130, 8502-8507.

[121] C.-A. Palma, J. Bjork, M. Bonini, M. S. Dyer, A. Llanes-Pallas, D. Bonifazi, M. Persson, P. Samorì, J. Am. Chem. Soc. 2009, 131, 13062-13071.

[122] A. Ciesielski, P. J. Szabelski, W. Rżysko, A. Cadeddu, T. R. Cook, P. J. Stang, P. Samorì, J. Am. Chem. Soc. 2013, 135, 6942-6950.

[123] M. El Garah, A. Dianat, A. Cadeddu, R. Gutierrez, M. Cecchini, T. R. Cook, A. Ciesielski, P. J. Stang, G. Cuniberti, P. Samorì, Small 2016, 12, 343-350.

[124] Y. Zhang, T. Gao, Y. Gao, S. Xie, Q. Ji, K. Yan, H. Peng, Z. Liu, ACS Nano 2011, 5, 4014-4022.

[125] F. Banhart, J. Kotakoski, A. V. Krasheninnikov, ACS Nano 2011, 5, 26-41. 